12,05

\title{
Влияние отжига на структурные, текстурные, термические, магнитные и люминесцентные свойства наночастиц фторида кальция
}

\author{
(C) В.Г. Ильвес ${ }^{1}$, С.Ю. Соковнин ${ }^{1,2}$, М.Г. Зуев ${ }^{2,3}$, М.А. Уймин ${ }^{2,4}$, M. Rähn ${ }^{5}$, J. Kozlova ${ }^{5}$, V. Sammelselg ${ }^{5,6}$ \\ ${ }^{1}$ Институт электрофризики УрО РАН, \\ Екатеринбург, Россия \\ ${ }^{2}$ Уральский фредеральный университет им. Б.Н. Ельцина, Екатеринбург, Россия \\ ${ }^{3}$ Институт химии твердого тела УрО РАН, \\ Екатеринбург, Россия \\ ${ }^{4}$ Институт фризики металлов им.М.Н.Михеева УрО РАН, \\ Екатеринбург, Россия \\ ${ }^{5}$ Institute of Physics, University of Tartu, \\ Tartu, Estonia \\ ${ }^{6}$ Institute of Chemistry, University of Tartu, \\ Tartu, Estonia \\ E-mail: ilves@iep.uran.ru
}

Поступила в Редакцию 15 мая 2019 г.

В окончательной редакции 15 мая 2019 г.

Принята к публикации 23 мая 2019 г.

Мезопористый нанокристаллический порошок $\mathrm{CaF}_{2}$ был получен методом импульсного испарения электронным пучком (PEBE) в вакууме. Удельная поверхность (SSA) нанопорошка (НП) $\mathrm{CaF}_{2}$ достигала $88.7 \mathrm{~m}^{2} \mathrm{~g}$. Исследовано влияние термического отжига на воздухе в интервале температур 200-900 ${ }^{\circ} \mathrm{C}$ на размер частиц, морфологию, текстурные, термические, магнитные и люминесцентные свойства NP. Наблюдали сильное отклонение от стехиометрии полученных наночастиц и значительное увеличение SSA после отжига при $200^{\circ} \mathrm{C}$. Полученный $\mathrm{CaF}_{2} \mathrm{HП}$ показал ферромагнитное (FM) поведение, Появление FM-отклика можно объяснить образованием структурых и радиационных дефектов. Анализ кривых импульсной катодолюминесценции (PCL) и намагниченности НП СаF 2 позволяет сделать выводы об их взаимосвязи.

Ключевые слова: наночастицы $\mathrm{CaF}_{2}$, импульсное электронное испарение.

DOI: $10.21883 /$ FTT.2019.11.48433.480

\section{1. Введение}

Нанофториды - важный класс наноматериалов, которые представляют большой научный интерес благодаря их широкому применению в различных областях науки и жизни. Простые и сложные нанофториды щелочноземельных металлов, легированные редкоземельными (RE) ионами, обнаруживают эффективную апконверсию [1], которая позволяет использовать нанофториды в качестве флуоресцентных меток для визуализации и биообнаружения, как in vitro, так и in vivo [2], или как новые антимикробные и антибиопленочные средства [3]. Наноразмерные термолюминесцентные люминофоры показывают увеличение люминесцентного выхода при облучении высокими дозами и повышенную радиационную стойкость [4]. Поэтому в последние годы снова вырос интерес к синтезу фторидных соединений, предлагаются новые и различные методы синтеза [5]. Основной интерес представляют исследования влияния наноразмерных частиц фторидов на их физические свойства [6].

$\mathrm{CaF}_{2}$ - важный оптический материал, с различными областями применения [7], например, для детектирования излучения в сцинтилляционной и термолюминесцентной дозиметрии. Как лазерный материал, $\mathrm{CaF}_{2}$ обладает множеством превосходных свойств, таких как высокий коэффициент пропускания от ультрафиолетовой до средней инфракрасной области спектра, легкая инкорпорация RE-ионов, низкий показатель преломления, высокая химическая стойкость, стабильность, негигроскопическое поведение и высокий порог лазерного повреждения. Альтернативными вариантами по сравнению с выращиванием монокристаллов фторидов представляются керамические технологии, основанные на порошковом синтезе с последующей обработкой [8]; ожидается замещение монокристаллов там, где требуются большие объемы и среды с большим усилением. В керамических технологиях, часто требуется предварительная обработка порошка, которая может сопровождаться различными структурными и морфологическими изменениями, поэтому необходимо понимание того, как свойства нанопорошка (НП) $\mathrm{CaF}_{2}$ зависят от дальнейшего отжига.

Различные методы применяются для синтеза наночастиц (НЧ) $\mathrm{CaF}_{2}$, например, сольво-термический [9], гидротермальный $[10]$, золь-гель $[11]$, реверсирования мицеллы [12], осаждения [13], распылительной сушки [14], микроволновой [15], полиольный [16], механохимический [17], пламенный синтез [18], термического разложения [19], лазерная абляция [20], синтез в нанореакторах, мицеллах и эмульсиях [21]. Тонкие и эпитаксиальные пленки $\mathrm{CaF}_{2}$ выращивали с помощью 
термического испарения [22], молекулярно-лучевой эпитаксии [23], импульсного лазерного испарения [24], электронно-лучевого испарения [25], атомно слоевого осаждения [26], металл-органического химического парового осаждения [27] и электроосаждения [28].

Производство наночастиц фторидных соединений является сложной задачей. Наночастицы очень чувствительны к воде и кислороду и загрязнение наночастиц фторидов примесями, например, такими как $\mathrm{O}^{2-}$ и $(\mathrm{OH})^{-}$очень вероятно, из-за сходства ионнных радиусов [29]; такие примеси могут ухудшать люминесцентные свойства [30], выступая в качестве центров тушения люминесценции, дефектов рассеяния света, ухудшения прозрачности и других. Наибольшая вероятность включения этих примесей в состав нанофторидов при использовании химических методов получения (мокром синтезе).

Преимущество метода импульсного испарения элеткронным пучком (PEBE) в сравнении с вышеуказанными способами получения фторидов заключается в возможности получать в условиях вакуума нанофториды не только в виде пленочных структур, но и нанопорошков различного состава, от простых до комплексных фторидов, в достаточном количестве, для проведения полного комплекса аналитических исследований полученных наноматериалов [31]. Отсутствие паров воды в процессе синтеза фторидов методом PEBE в вакууме, в частности, практически полностью исключает риск появления нежелательной реакции пирогидролиза при высокой температуре в испарительной камере. К тому же, для синтеза и роста наночастиц /нанопокрытий не требуется применения опасных фторсодержащих реактивов. Люминесцентные свойства фторидов исследованы достаточно хорошо [32-37]. В настоящее время стремительно развиваются исследования дефектной структуры и люминесцентных свойств нанофторидов, в частности, фторида $\mathrm{CaF}_{2}$ [38-40]. Однако, при высочайшем интересе к спектральным свойствам нанофиторидов, практически отсутствуют исследования магнитных свойств наночастиц $\mathrm{CaF}_{2}$. В объемном состоянии $\mathrm{CaF}_{2}$ показывает диамагнитное поведение. По известным нам литературным данным, ферромагнитное состояние при комнатной температуре (ФМКТ) наночастиц $\mathrm{CaF}_{2}$ было обнаружено в работе [41]. Намагниченность насыщения $\mathrm{CaF}_{2}$ в наносостоянии, приведенная в [41] данной работе, составила от 0.05 до $0.15 \mathrm{emu} / \mathrm{g}$. Каких-либо объяснений происхождения ферромагнетизма в наночастицах $\mathrm{CaF}_{2}$ в данной работе нет.

Целью настоящей работы является исследование эволюции структурных, термических, магнитных и люминесцентных характеристик нанокристаллических порошков $\mathrm{CaF}_{2}$, полученных в вакууме, после термической обработки порошков на воздухе.

\section{2. Методика эксперимента}

НП $\mathrm{CaF}_{2}$ получали с помощью импульсного электронного испарения в вакууме на установке
Таблица 1. Параметры элементарной ячейки $(a)$, полуширины дифракционных пиков (FWHM) исходного и отожженных образцов $\mathrm{CaF}_{2}$

\begin{tabular}{c|c|l}
\hline Sample & $a, \mathrm{~nm}$ & FWHM \\
\hline S0 & $5.4606(6)$ & $0.141(1)$ \\
S200 & $5.4582(5)$ & $0.22(3)$ \\
S900 & $5.4588(6)$ & $0.101(4)$
\end{tabular}

НАНОБИМ-2 [42,43] (остаточное давление 4 Рa). Осаждение НП проводилось на стеклянные подложки, размещенные вокруг мишени на расстоянии $10-15 \mathrm{~cm}$ от центра мишени (табл. 1).

Мишени в форме таблеток, изготавливались из микронного порошка $\mathrm{CaF}_{2}$ марки ОСЧ (TУ TU 6-09-2412-84), SSA $=18.47 \mathrm{~m}^{2} / \mathrm{g}$ ) с помощью ручного пресса. Таблетки спекали в электропечи при температуре $900^{\circ} \mathrm{C}$ на воздухе (без изотермической выдержки) на подложке из YSZ $\left(\mathrm{Y}_{2} \mathrm{O}_{3}\right.$-doped $\left.\mathrm{ZrO}_{2}\right)$ и затем охлаждали вместе с печью до комнатной температуры. Использовался следующий режим работы установки Нанобим-2: ускоряющее напряжение $38 \mathrm{kV}$, ток пучка $-0.2 \mathrm{~A}$, длительность импульса $100 \mu \mathrm{s}$, частота импульсов - $50 \mathrm{~Hz}, \quad$ развертка пучка на мишени $-2.5 \mathrm{~cm}^{2}$, время испарения $50 \mathrm{~min}$. Наночастицы осаждались на подложки из оконного стекла большой площади, размещенные на рассотянии $10-15 \mathrm{~cm}$ от центра мишени. Дальнейший изотермический отжиг $\mathrm{HП} \mathrm{CaF}_{2}$ проводился в алундовых тиглях на воздухе при температуре 200, 400 и $900^{\circ} \mathrm{C}$ в течении $10 \mathrm{~min}$. Далее, в этой статье образцы $\mathrm{CaF}_{2}$, исходный и отожженные при температуре 200,400 и $900^{\circ} \mathrm{C}$ обозначались S0, S200, S400 и S900 соответсвенно.

При анализе свойств НП использовались следующие диагностики. Удельная поверхность порошков SSA определялась методом Брунауэра-Эммета-Тейлора (BET) на установке Micromeritics TriStar 3000 после дегазации исследуемого материала в вакууме при температуре $100^{\circ} \mathrm{C}$ в течение $1 \mathrm{~h}$. Рентгенофазовый анализ (XRD) выполнялся на дифрактометре XRD 7000 Shimadzu (Япония); сьемку образцов производили на $\mathrm{Cu} K_{\alpha}$-излучении с никелевым фильтром в интервале углов по $2 \theta$ от 20 до $90^{\circ}$. Сканирующая электронная микроскопия (СЭМ) использовалась для визуализации и изучения морфологии поверхности наночастиц $\mathrm{CaF}_{2}$. СЭМ-изображения высокого разрешения с различным увеличением получали с использованием микроскопа Helios NanoLab 600 (FEI). Испытуемый материал закрепляли на держателе с помощью углеродной проводящей клейкой ленты (ТАAB). СЭМ проводили также в просвечивающем (СПЭМ) режиме. Для получения изображений в просвечивающем режиме, НП диспергировались в изопропаноле и каплю полученного раствора наносили на опорную-сетку, покрытую углеродной пленкой. Энергодисперсионный 
рентгеновский микроанализ (ЭДРМА) выполняли в сканирующем электронном микроскопе LEO982 (Zeiss) оснащенном энерго-дисперсионным рентгеновским спектрометром (Oxford Instruments). Для ЭДРМА образцы НП диспергировались с помощью ультразвуковой обработки в изопропаноле, затем наносились на $\mathrm{Cu}-\mathrm{Zn}$ подложку и высушивались в чашке Петри. Энергия первичных электронов, использованная для определения элементного состава, составляла $3 \mathrm{keV}$. Анализ спектров проводился с использованием программного обеспечения INCA (Oxford Instruments). Размеры наночастиц НП наблюдали с помощью просвечивающей электронной микроскопии (ПЭМ) на микроскопе Titan 200 (FEI) при ускоряющем напряжении $200 \mathrm{kV}$. Кривые намагничивания записывались на весах Фарадея (чувствительность $\left.10^{-5} \mathrm{emu} / \mathrm{g}\right)$. Зависимость намагниченности от температуры измерялась в атмосфере $\mathrm{Ar}$ и $\mathrm{H}_{2}$. Термический анализ НП с помощью методов термогравиметрии (TG) и дифференциальной сканирующей калориметрии (DSC) проводился на синхронном термоанализаторе STA-409-PC Luxx, совмещенном с масс спектрометром QMS-403C фирмы NETZSCH. Спектры фотолюминесценции (ФЛ) записаны при комнатной температуре на спектрометре МДР-204 (дейтериевая лампа, фотоэлектронный умножитель R928 фирмы Hamamatsu), a спектры импульсной катодолюминесценции (ИКЛ) - на установке КЛАВИ 1 [44].

\section{3. Результаты и обсуждение}

\section{1. Синтез нанофторидов и отжиг центров окраски}

На рис. 1 показан кратер на поверхности мишени из $\mathrm{CaF}_{2}$, образовавшийся на поверхности мишени, при испарении импульсным электронным пучком в вакууме в течении $50 \mathrm{~min}$

На рис. $1, a, b$ видно, что боковая поверхность мишени имеет бело-розовый цвет. Розовый цвет указывает на образование центров окраски в НП $\mathrm{CaF}_{2}$ непосредственно в процессе получения нанофторида методом PEBE. При испарении мишени на образующиеся пары идет одновременное воздействие нескольких факторов: (i) тормозного рентгеновского излучения, возникающего при взаимодействии первичных электронов с энергией $40 \mathrm{keV}$ с испаряемой мишенью, (ii) первичных электронов (мишень установлена под углом $45^{\circ}$ по отношению к первичному пучку); (iii) паров восстановленного в процессе испарения металлического Са. По сути, в методе $\mathrm{PEBE}$ рост наночастиц $\mathrm{CaF}_{2}$ происходит в присутствии паров восстановленного Са, аналогично традиционному аддитивному окрашиванию, и одновременно, присутствует воздействие рентгеновского и светового излучения, и в конечном итоге, при осаждении паров на холодную подложку происходит закалка паров на холодной подложке. На рис. 1, $c$ показано изменение
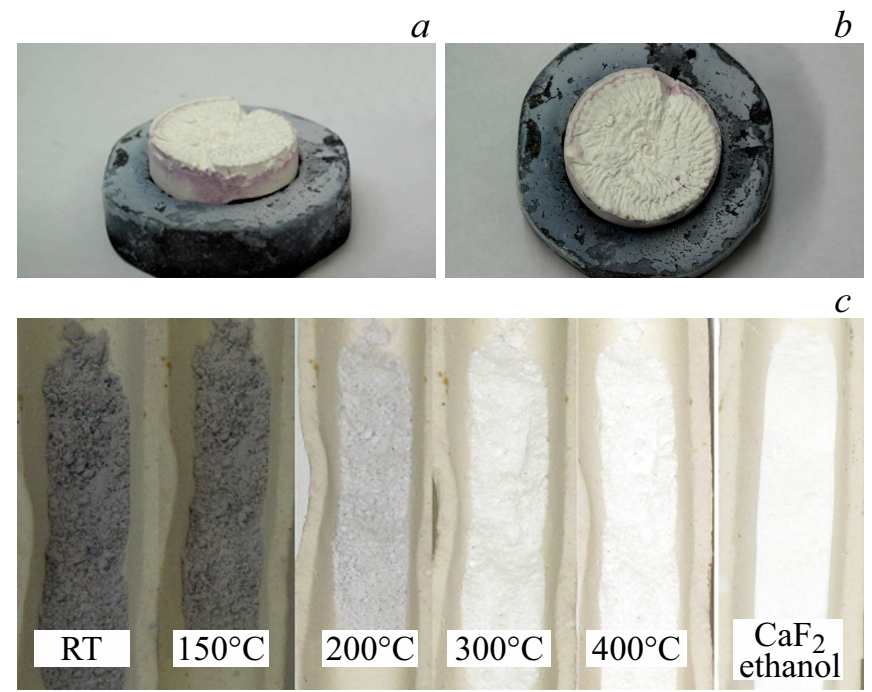

Рис. 1. Кратер в мишени из $\mathrm{CaF}_{2}$, образовавшийся в результате испарения импульсным электронным пучком в вакууме (мишень при испарении размещалась в тигле из реакторного графита. Вид мишени сбоку $-a)$; вид мишени сверху $-b$ ). Изменение цвета НП $\mathrm{CaF}_{2}$ при ступенчатом отжиге на воздухе в электропечи. Изотермическая выдержка при каждой температурной остановке - $10 \mathrm{~min}$. Эталон - микронный порошок $\mathrm{CaF}_{2}$, марка ОСЧ, $\left.\mathrm{CCCP} c\right)$.

цвета НП $\mathrm{CaF}_{2}$ при термическом отжиге центров окраски в диапазоне температуры от комнатной (RT) до $400^{\circ} \mathrm{C}$. Сливовый цвет исходного НП после отжига при температуре $400^{\circ} \mathrm{C}$ изменился до белого, и почти сравнялся по яркости с эталонным микронным порошком, из которого изготавливалась мишень. Центры окраски фторидов, индуцированные различными видами излучений, изучались с середины 20 столетия многими авторами [45-48] обычно, с помощью измерения оптических спектров поглощения как функции поглощенной дозы. Центры окраски, индуцированные различными видами излучения, характеризуются схожими полосами поглощения при 225, 260, 335, 385, 455, 550 и $580 \mathrm{~nm}$ [46-49]. Есть много работ об оптических спектрах поглощения рентгеновских лучей, $\gamma$-лучей, электронов, нейтронов облученых кристаллов $\mathrm{CaF}_{2}$ [38,48,50-55]. Ранние исследования $\mathrm{CaF}_{2}$, облученного электронами, рентгеновскими лучами и нейтронами показали, что поглощение и люминесценция $\mathrm{CaF}_{2}$ связаны основном с собственными дефектами (F-центры и их агрегаты (M- и R-центры), Н-центры или самозахваченные дырки (Vk-центры). Спектры поглощения облученных фторидов с центрами окраски характеризуются большим вариабельностью, высокой „чувствительностью“ к условиям выращивания и окрашивания, к присутствию различных примесей [56]. В частности, есть работы посвященные изучению воздействия электронного пучка на кристаллы $\mathrm{CaF}_{2}$ с энергией электронов 50-75 кэВ [57,58]. В работе [49] оптическая плотность облученного нейтронами кристалла 


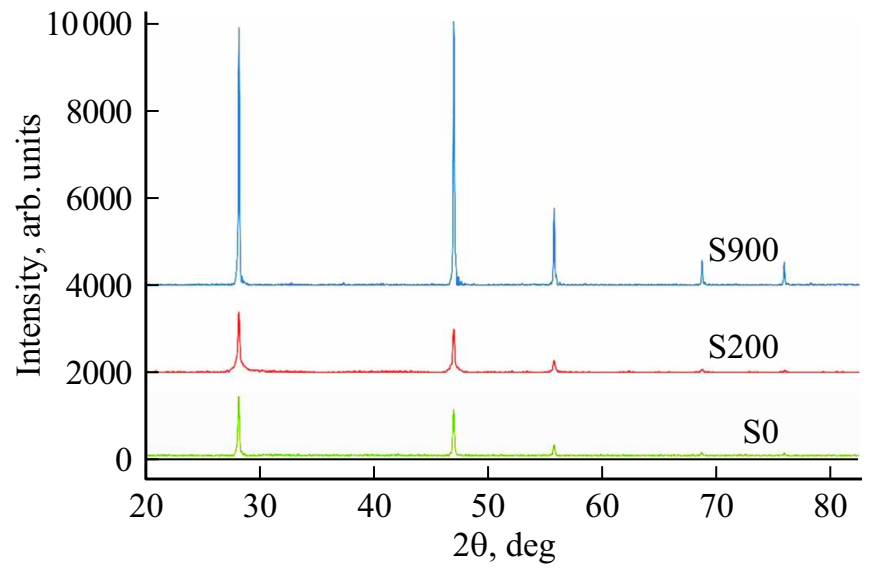

Рис. 2. Дифрактограммы исходного (S0) и отожженных (S200 и $\mathrm{S} 900)$ образцов.

$\mathrm{CaF}_{2}$ резко уменьшалась при температуре $523 \mathrm{~K}\left(250^{\circ} \mathrm{C}\right)$ и это означало, что концентрация металлических коллоидов Са в стремилась к нулю при $250^{\circ} \mathrm{C}$. Однако, в нашем случае изменение окраски НЧ, связанное с исчезновением коллоидов $\mathrm{CaF}_{2}$ (рис. $1, \mathrm{c}$ ), заканчивается при более высокой температуре $\left(400^{\circ} \mathrm{C}\right)$.

\section{2. Рентгенофазовый анализ}

На рис. 2 приведены рентгеновские дифрактограммы образцов S0, S200 и S900. Образцы однофазные, присутствует только флюорит (JCPDS card No 00-035-0816, cubic, $F m 3 m$ space group).

Параметры элементарной ячейки и полуширины пиков приведены в табл. 1 Параметры элементарной ячейки образцов близки между собой, наименьшую FWHM имели образцы, отожженные при $900^{\circ}$, наибольшую при $200^{\circ} \mathrm{C}$. Дифракционные пики от примесных фаз на дифрактограмммах на рис. 2 отсутствовали, однако, мы не исключаем возможность присутствия в образцах примесных фаз $\mathrm{CaO}, \mathrm{Ca}(\mathrm{OH})_{2}$ и $\mathrm{CaCO}_{3}$, особенно в образце S900, как вследствие окисления НЧ металлического $\mathrm{Ca}$, которые образовывались в $\mathrm{HП} \mathrm{CaF}_{2}$ на стадии синтеза, так и адсорбции паров воды и $\mathrm{CO}_{2}$ из окружающей атмосферы при хранении нанофторида. Наибольшее уширение пиков образца S200 после непродолжительного низкотемпературного отжига можно объяснить разрыхляющим действием формирующихся при отжиге тонких фаз из карбида и гидрооксида кальция (примесные фазы формируются по поверхности наночастиц фторида кальция), которые имеют отличные от кубической флюоритной решетки $\mathrm{CaF}_{2}$ - гексагональную и тригональную решетки соответственно. Сужение дифракционных пиков у образца $\mathrm{S900}$ указывает на усиление его кристалличности и на доминирующую роль примесной фазы $\mathrm{CaO}$, которая также имеет кубический тип решетки, как у флюорита.

\section{3. Текстурный анализ}

Результаты измерения текстурных свойств микронного порошка из которого изготавливалась мишень (образец $\left.S_{\text {target }}\right)$ и образцов НП S0,S200,S400 и S900 показаны в табл. 2. Все порошки, за исключением образца S900, относятся к мезопористых порошкам, на что указывает гистерезис изотерм адсорбции-десорбции азота IV типа. Образцы микронных порошков $S_{\text {target }}$ и $\mathrm{S} 900$ показали унимодальное распределение пор по размеру. Образцы нанопрошков S0, S200 и S900 имели мультимодальное распределение пор по размеру, что легко объяснимо, исходя из пространственного строения агрегатов из НЧ (см. далее раздел 3.5.).

После короткого отжига (10 min) при низкой температуре $\left(200^{\circ} \mathrm{C}\right)$ вследствие удаления адсорбированной воды с поверхности НЧ, удельная поверхность НЧ значительно увеличилась, при этом почти в три раза вырос объем межчастичных пор НП (табл. 2). Отметим, что объем пор образца S200 $\left(0.66 \mathrm{~cm}^{3}\right)$ даже превосходил объем пор НП Аэросил $300\left(0.56 \mathrm{~cm}^{3} / \mathrm{g}\right)$ со значительно большей величиной SSA $=295 \mathrm{~m}^{2} / \mathrm{g}$ [59]. После отжига образца S400 поверхность уменьшилась до $52.4 \mathrm{~m}^{2} / \mathrm{g}$, общий объем пор и диаметр пор сопоставимы с исходными значениями. Подобный рост SSA мы наблюдали после отжига на воздухе НП $\mathrm{BaF}_{2}$ при температуре $200^{\circ} \mathrm{C}$, SSA выросла с 19.0 до $34.8 \mathrm{~m}^{2} / \mathrm{g}$ [60]. Данные табл. 2 показывают, что текстурные свойства с дальнейшим увеличением температуры отжига постепенно снижались и отжиг при температуре $900^{\circ} \mathrm{C}$ привел к трансформиции мезопористого НП в субмикронный порошок.

Удельная поверхность неотожженого НП $\mathrm{CaF}_{2}$ S0 была сопоставима по порядку величины с удельной поверхностью НП, полученными разными методами [18,61-63].

В работе [64] измерение пористости тонких пленок щелочно-земельных флюоридов $\left(\mathrm{CaF}_{2}, \mathrm{BaF}_{2}\right.$ и $\left.\mathrm{MnF}_{2}\right)$ осажденных методом термического испарения на стеклянные подложки показало, что пористость уменьшается с ростом температуры подложки. Учитывая сходство процессов осаждения наночастиц на подложку при термическом испарении и $\mathrm{PEBE}$, при использовании последнего возможно получение мезопористых НП с большей SSA за счет уменьшения частоты следования импульсов (по сути, за уменьшения температуры на

Таблица 2. Текстурные свойства образцов $\mathrm{HП} \mathrm{CaF}_{2}$ до и после отжига

\begin{tabular}{c|c|c|c}
\hline Образец & $\mathrm{SSA}\left(\mathrm{m}^{2} / \mathrm{g}\right)^{a}$ & $V_{\mathrm{p} \text {-Total }}\left(\mathrm{cm}^{3} / \mathrm{g}\right)^{b}$ & $\mathrm{D}_{\text {ВJH }}(\mathrm{nm})^{c}$ \\
\hline$S_{\text {target }}$ & 18.5 & 0.13 & 25 \\
S0 & 64.3 & 0.25 & 21 \\
S200 & 88.7 & 0.66 & 29 \\
S400 & 52.4 & 0.30 & 23 \\
S900 & 1.1 & 0.0025 & 37
\end{tabular}

${ }^{a}$ BET surface area. ${ }^{b}$ Total pore volume. ${ }^{c}$ Pore diameter by BJH desorption. 
Таблица 3. Результаты ЭДРМА образцов S0 и S200

\begin{tabular}{|c|c|c|c|c|c|c|c|c|c|c|c|c|c|}
\hline \multirow{3}{*}{$\begin{array}{c}\text { Элемент } \\
\mathrm{C}\end{array}$} & \multirow{3}{*}{$\begin{array}{c}\text { Тип } \\
\text { линии }\end{array}$} & \multicolumn{6}{|c|}{$\mathrm{Wt} \%$} & \multicolumn{6}{|c|}{ At $\%$} \\
\hline & & \multicolumn{3}{|c|}{ S0 } & \multicolumn{3}{|c|}{ S200 } & \multicolumn{3}{|c|}{ S0 } & \multicolumn{3}{|c|}{ S200 } \\
\hline & & 3.5 & 2.8 & 2.6 & 3.2 & 3.2 & 2.8 & 7.9 & 6.3 & 6.0 & 7.1 & 7.4 & 6.4 \\
\hline $\mathrm{O}$ & K серия & 1.5 & 1.2 & 1.0 & 1.5 & 1.5 & 1.5 & 2.4 & 2.1 & 1.9 & 2.6 & 2.6 & 2.5 \\
\hline $\mathrm{F}$ & $\mathrm{K}$ серия & 36.9 & 32.8 & 30.6 & 33.8 & 33.5 & 33.7 & 51.4 & 47.9 & 45.6 & 48.5 & 48.0 & 48.6 \\
\hline $\mathrm{Ca}$ & К серия & 58.1 & 63.2 & 65.8 & 61.5 & 61.8 & 62.0 & 38.3 & 43.7 & 46.5 & 41.8 & 42.0 & 42.5 \\
\hline Сумма: & & 100 & 100 & 100 & 100 & 100 & 100 & 100 & 100 & 100 & 100 & 100 & 100 \\
\hline
\end{tabular}

поверхности испаряемого слоя мишени) и сокращения времени испарения.

\section{4. Энерго-дисперсионный рентгеновский микроанализ}

Результаты энерго-дисперсионного рентгеновского микроанализа (ЭДРМА) наночастиц $\mathrm{CaF}_{2}$ до и после отжига приведены в табл. 3. Анализ показал отсутствие магнитных примесей $(\mathrm{Fe}, \mathrm{Co}$ и $\mathrm{Ni})$ в образцах. Основные примеси в $\mathrm{HЧ} \mathrm{CaF}_{2}$ - углерод и кислород. Они могли быть адсорбированы из паров масла в вакуумной камере в процессе синтеза НЧ или из окружающего воздуха при хранении.

Сильное нарушение стехиометрии наблюдалось в обоих образцах. Соотношение атомов $\mathrm{F}: \mathrm{Ca}=1.15$ в неотожженном образце S0 практически не изменилось после отжига при температуре $200^{\circ} \mathrm{C}$ и составило $\mathrm{F}: \mathrm{Ca}=1.13$ для образца S200.Избыток кальция (дефицит ионов фтора) в образцах S0 и S200 был обусловлен двумя факторами: восстановлением металлического кальция при испарении $\mathrm{CaF}_{2}$ в условиях вакуума и образованием центров окраски, содержащих наночастицы металлического $\mathrm{Ca}$, в результате воздействия первичных электронов и рентгеновского тормозного излучения на первичные частицы, содержащиеся в паро-газовом облаке над поверхностью испаряемой мишени и на осажденные на подложку НЧ, в течение всего цикла испарения. Концентрация примесного углерода после отжига осталась почти на прежнем уровне (незначительно увеличилась с 2.95 до 3.06 mass.\% (усредненная оценка)). Отсутствие десорбции углерода согласуется с данными термического анализа образца S0 (будет показано ниже в разделе 3.7), где из синхронных кривых DSC и TG следует, что процесс удаления углеродсодержащих примесей начался с температуры выше $200^{\circ} \mathrm{C}$.

Было проведено элементное картирование образцов S0 и S200 (здесь не показано). Карты легких элементов показали однородное распределение элементов на исследованных участках образцов. Аномальное распределение Са (на элементных картах Са обоих образцов не просматриваются формы анализируемых участков) показало наличие сильной нестехиометрии в неотожженном образце и ее сохранение после короткого отжига об- разца при температуре $200^{\circ} \mathrm{C}$. Отсутсвие кластеров на картах всех исследованных элементов важно при дальнейшем анализе магнитныхт свойств НЧ, т. к. указывает на гомогенное распределение примесей и ионов фтора в решетке $\mathrm{CaF}_{2}$.

\section{5. Сканирующая электронная микроскопия}

На рис. 3 показаны СЭМ снимки образцов S0 и S200, сделанные с большим разрешением и в просвечивающем режиме СПЭМ II. Пространственная 3D структура агломератов $\mathrm{HЧ} \mathrm{CaF}_{2}$, образованная мелкими НЧ хорошо видна на рис. 3, $a$. На СПЭМ снимках рис. 3, $b, d$ представлены агрегат и агломерат из неотожженных НЧ $\mathrm{CaF}_{2}$. Хорошо видна межчастичная пористость вышуказанных наноструктур. Степень спекания НЧ в агрегате показана на рис. 3, $d$. На СПЭМ II снимках (рис. 3,e,f) показаны структуры агрегата и агломерата отожженного образца S200. Из морфологического анализа следует, что отжиг при температуре $200^{\circ} \mathrm{C}$ не привел к видимому изменению морфологии неотожженных НЧ.

\section{6. Просвечивающая электронная микроскопия}

На рис. 4 показаны TEM/HRTEM and SAED снимки образцов S0 и S200. Размер отдельных неотожженных НЧ (рис. 4, $a, b$ ) составлял около 10-20 nm. Кристаллические частицы в основном имели квазисферическую форму (рис. 4, $b$ ). Большая часть НЧ была объединена в агрегаты (рис. 4,c), размером от десятков до нескольких сотен nm. Агрегаты образовались из первичных частиц парового облака, в сложном процессе зародышеобразования, роста, коагуляции и интенсивного слияния. Отдельные НЧ в агрегатах соединены спайками различной толщины и протяженности, как было показано ранее на SEM снимках на рис. $4, d$, поэтому их достаточно трудно дезагрегировать. В свою очередь, агрегаты соединены между собой с помощью сил слабого взаимодействия в более крупные пространственные 3D структуры-агломераты, размером от $0.5 \mu$ до нескольких единиц $\mu \mathrm{m}$. (рис. $4, d$ ), которые могут быть относительно легко деагломерированы, например, с помощью ультразвуковой обработки. Электронограмма на рис. 4,e 

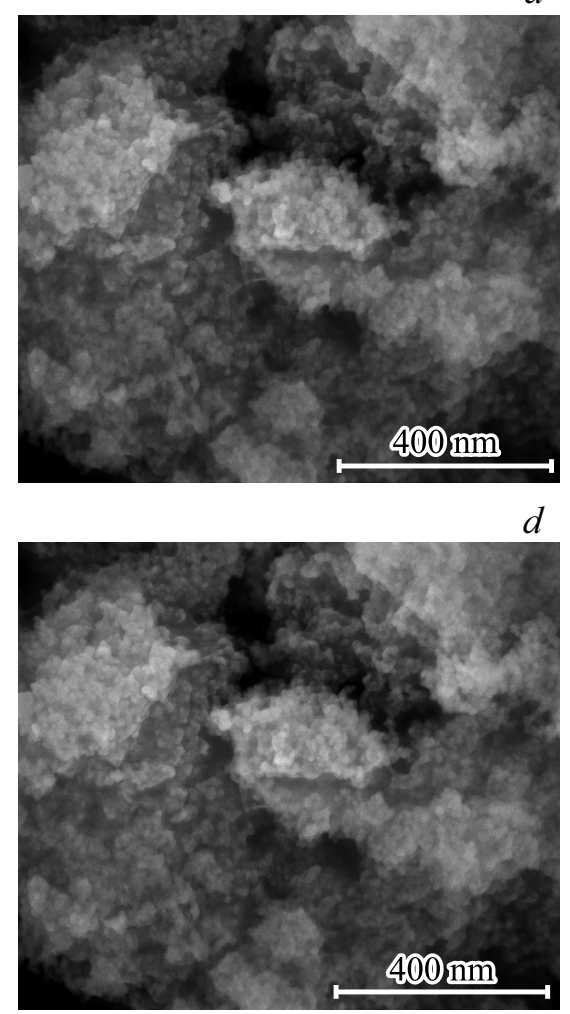

$b$
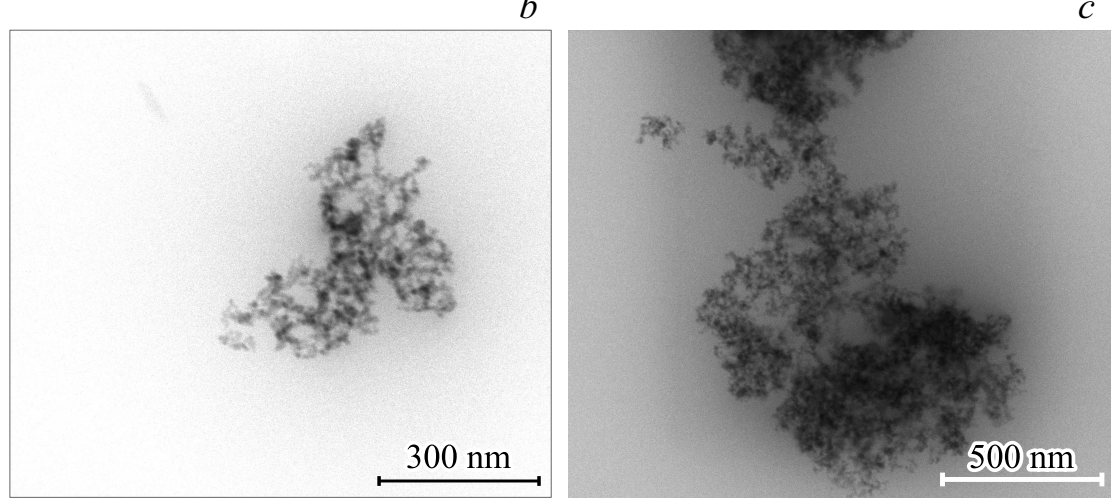

$e$

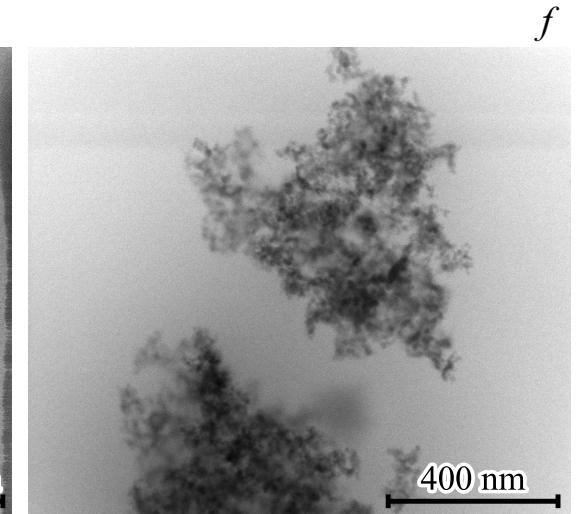

Рис. 3. Морфология НП $\mathrm{CaF}_{2}$ на СЭМ и СПЭМ II снимках неотожженного $\mathrm{S} 0$ и отожженного образца $\left.\mathrm{S} 200: a\right)$ типичная 3D структура НП $(\mathrm{S} 0), b)$ агрегат из НЧ $(\mathrm{S} 0), c)$ агломерат из НЧ $(\mathrm{S} 0), d)$ пористая структура НП, с сильно спеченными НЧ (S0), e) агрегат НЧ в отожженном образце $\mathrm{S} 200, f)$ агломерат НЧ в образце $\mathrm{S} 200$.

подтверждает кристаллическую флюоритную структуру образовавшихся при испарении $\mathrm{PEBE} \mathrm{HЧ} \mathrm{CaF}_{2}$ и согласуется с данными РФА. Отжиг при температуре $200^{\circ} \mathrm{C}$ не привел к заметному изменению морфологии, размера и кристалличности НЧ, что подтвердили ТЕМ (рис. $4, f, g, h$ ) и SAED (рис. $4, i$ ) снимки образца S200.

\section{7. Термический анализ}

На кривой DSC (рис. 5, $a$ ) образца S0 в температурном диапазоне $1\left(40-210^{\circ} \mathrm{C}\right)$ из образца происходило удаление адсорбированной воды (эндотермический пик). Убыль массы составила около $4.5 \mathrm{mass} \%$ (участок I на кривой $\mathrm{TG}$, рис. $5, a)$. В диапазоне $2\left(210-440^{\circ} \mathrm{C}\right)$ одновременно проходили несколько процессов (кристаллизация аморфной фракции образца; выделение летучих фракций, содержащих $\mathrm{CO}_{2}$ и отжиг центров окраски, образовавшихся в НЧ под действием рентгеновского излучения в процессе испарения мишени. По литературным данным отжиг центров окраски в $\mathrm{CaF}_{2}$ начинается с температуры около $180^{\circ} \mathrm{C}$, что хорошо согласуется с визуальным наблюдением изменения окраски нашего образца, показанным на рис. 5. Отжиг центров окраски сопровождался протяженным экзотермическим пиком на кривой DSC в температурном диапазоне от 210 до $440^{\circ} \mathrm{C}$. В температурном диапазоне $3\left(440-580^{\circ} \mathrm{C}\right)$ заметных термических превращений не наблюдалось. Убыль массы образца окончательно завершилась при температуре около $580^{\circ} \mathrm{C}$ и составила 10.2 mass\% (см. участки I и II на кривой TG). Начиная с температуры около $580^{\circ} \mathrm{C}$, на кривой DSC в температурном диапазоне $4\left(580-760^{\circ} \mathrm{C}\right)$ появился заметный протяженный (от 580 до $\sim 760^{\circ} \mathrm{C}$ ) экзотермический пик. Хорошо известно, что при нагревании на воздухе $\mathrm{CaF}_{2}$ (как и в нашем случае) наблюдается диффузия кислорода в решетку $\mathrm{CaF}_{2}$ [65] и возможны две реакции: реакция окисления $\mathrm{CaF}_{2}+1 / 2 \mathrm{O}_{2} \rightarrow \mathrm{CaO}+\mathrm{F}_{2}$ (I) или нежелательная реакция пиролиза $\mathrm{CaF}_{2}+\mathrm{H}_{2} \mathrm{O} \rightarrow \mathrm{CaO}+2 \mathrm{HF}$ (2) (в случае протекания реакции пиролиза (2) с выделением кислоты существовала опасность повреждения измерительной ячейки термоанализатора, поэтому нагрев образцов мы ограничили температурой $\left.1000^{\circ} \mathrm{C}\right)$. Однако, по известным литературным данным [66], реакция пиролиза в большинстве случаев начинается при более высокой температуре, порядка $780-800^{\circ}$, что указывает на малую вероятность начала реакции пиролиза при относительно низкой температуре $580^{\circ} \mathrm{C}$. По нашему мнению, экзотермический пик отвечает реакции окисления $\mathrm{CaF}_{2}(1)$, при которой происходит вытеснение атомов фтора из узлов кристаллической решетки атомами кислорода, а потеря массы образцом в температурном диапазоне от 580 до $\sim 665^{\circ} \mathrm{C}$ компенсируется 
$a$
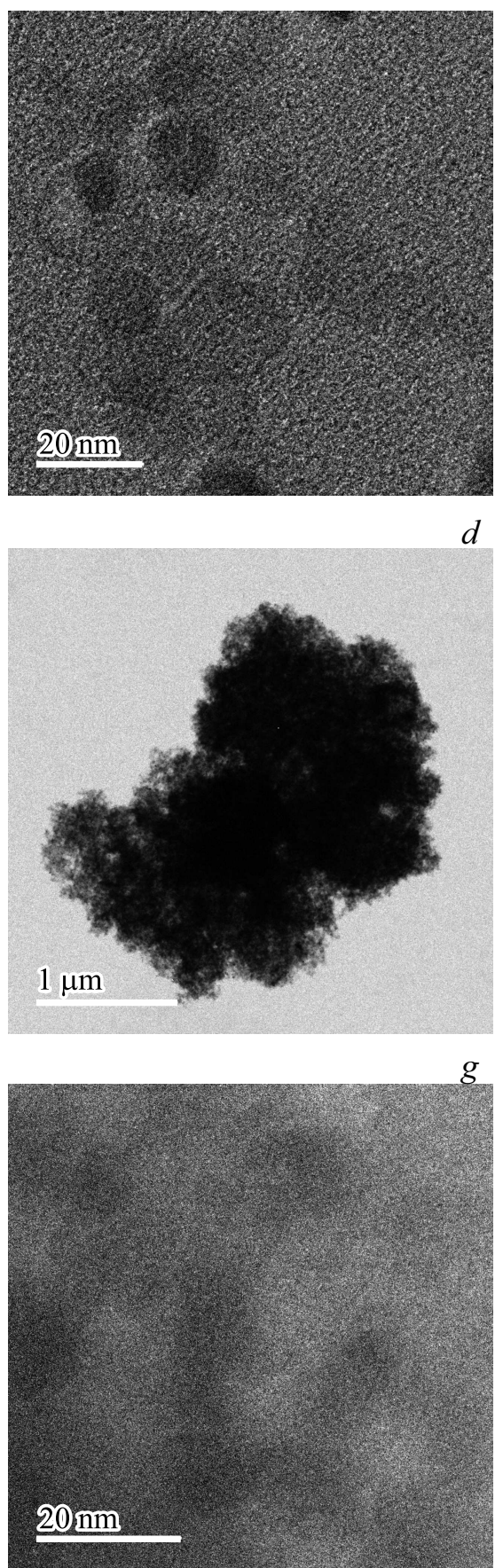

$b$
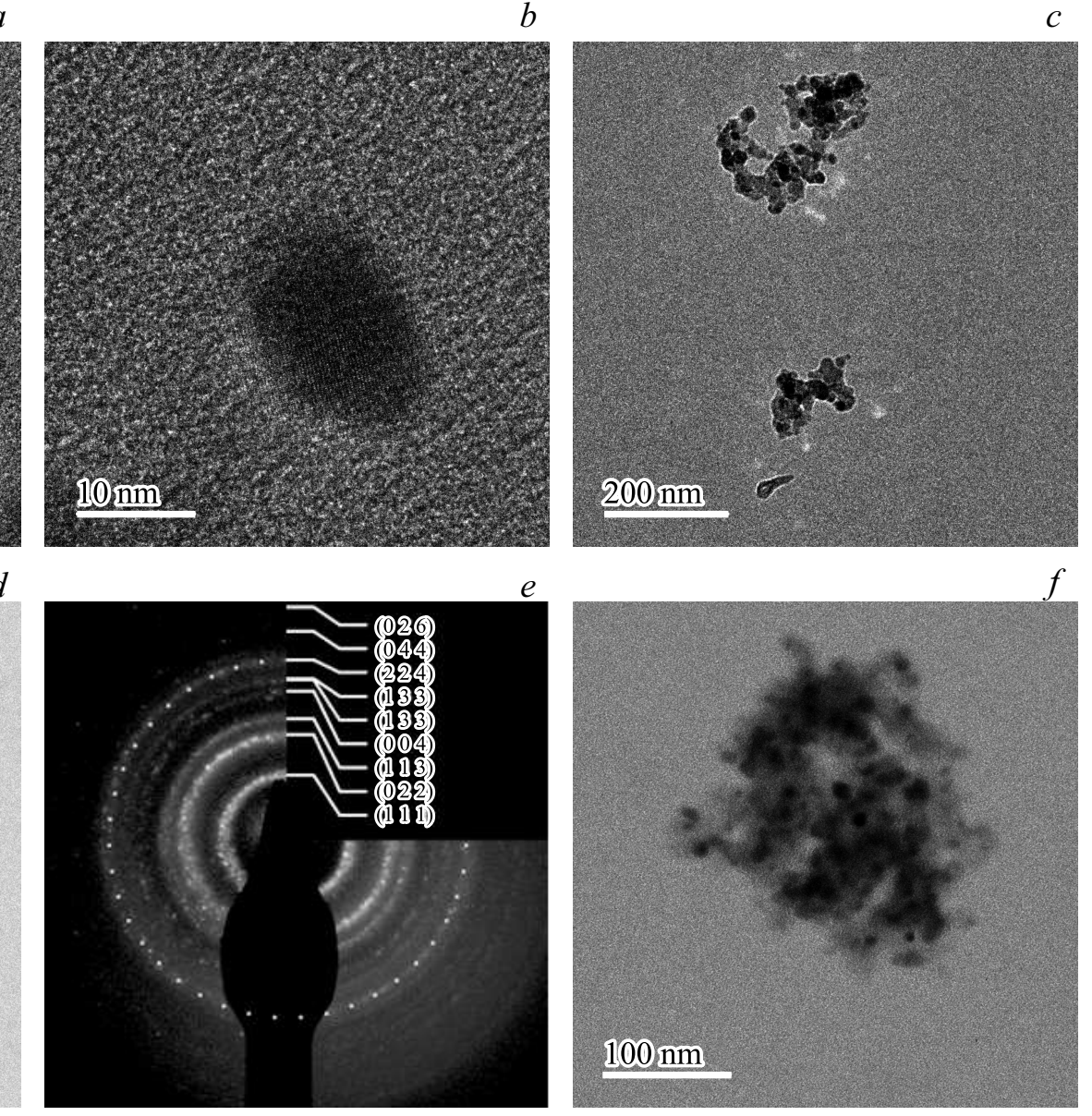

$h$
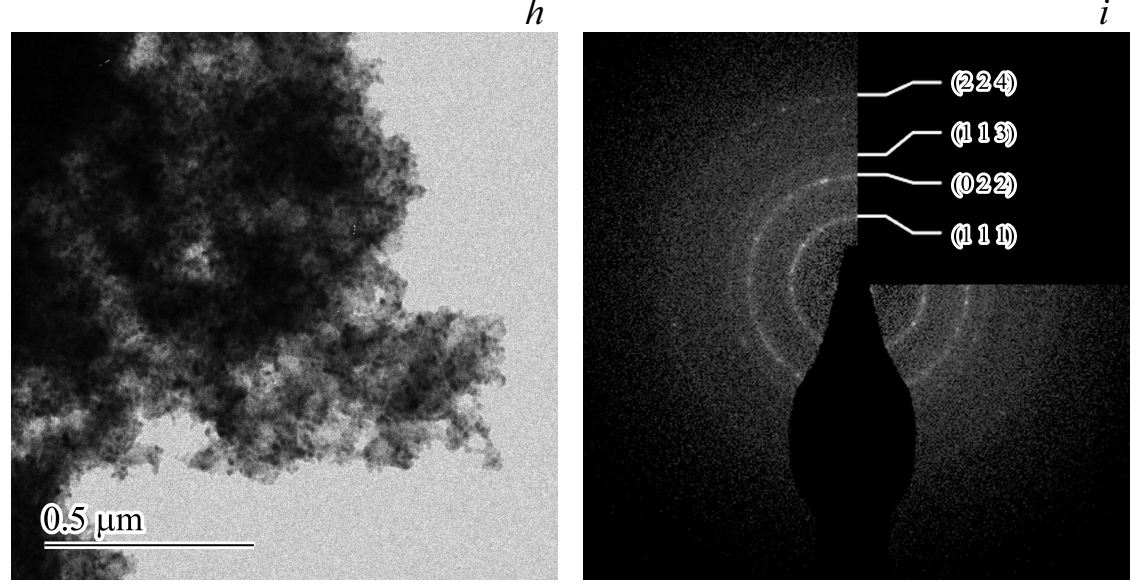

Pис. 4. TEM/HRTEM и SAED снимки образцов S0 $(a-e)$ и $\mathrm{S} 200(f-i)$.

набором массы за счет реакции окисления, поэтому в вышеуказанном диапазоне температуры не происходило изменение масс образца. При температуре $\sim 665^{\circ} \mathrm{C}$ на кривой TG (участок III) наблюдался непрерывный рост массы образца S0, вызванный усилением кинетики образования оксида $\mathrm{CaO}$ с ростом температуры. Рост массы образца непрерывно продолжался вплоть до окончания нагрева до $1000^{\circ} \mathrm{C}(1.8$ wt.\%) и был вызван образованием оксида $\mathrm{CaO}$.
Однако, самое заметное термическое превращение образец S0 испытал в 5 температурном диапазоне $\left(760-970^{\circ} \mathrm{C}\right)$. Мощный эндотермический пик на кривой DSC появился при температуре $760^{\circ} \mathrm{C}$. Эндотермический тип реакции однозначно указывает на образование жидкой фазы в образце при данной температуре. Жидкая фаза могла появиться в результате двух реакций: (1) плавления металлических наночастиц Са (температура плавления объемного Са равна $838.85^{\circ} \mathrm{C}$ ), 

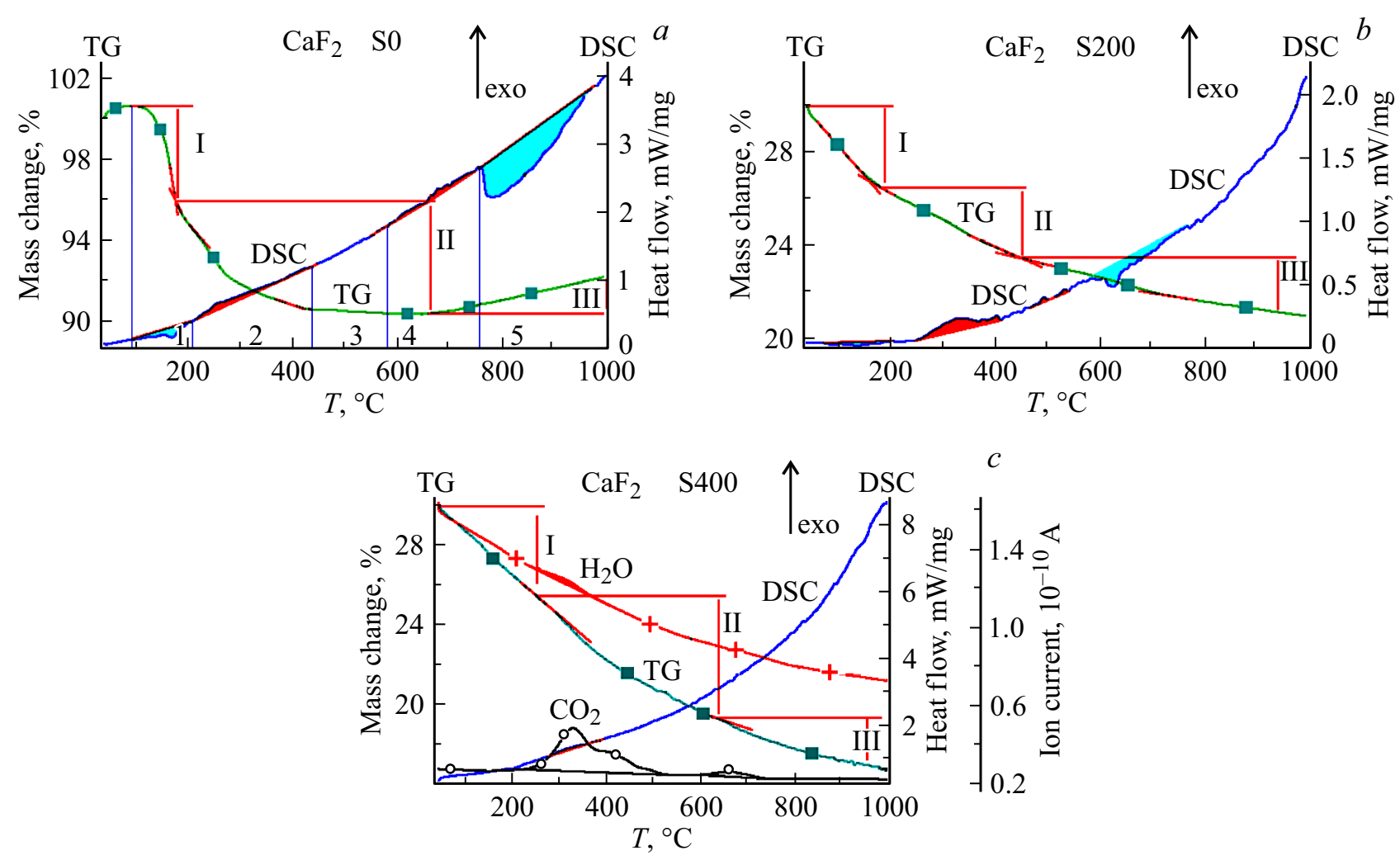

Рис. 5. Термограммы нагрева синхронного DSC-TG анализа, в диапазоне $\left.40-1000^{\circ} \mathrm{C}: a\right)$ образец S0; $\left.b\right)$ образец S200, c) образец S400. Кривые масс-спектров $\mathrm{H}_{2} \mathrm{O}$ и $\mathrm{CO}_{2}$ образца $\mathrm{S} 400$ отмечены значками „крест“ и „круг“ соответсвенно.

который, как широко известно, образуется в $\mathrm{CaF}_{2}$ при его облучении электронами и другими типами излучения [67-70]; (2) реакции образования жидкой фазы на границах зерен образца между металлической $(\mathrm{Ca})$ и фторидной фазами $\left(\mathrm{CaF}_{2}\right)$ вследствие протекания эвтектической реакции при температуре равной $760^{\circ} \mathrm{C}$ $\left(\mathrm{L}_{\text {eut }} \rightarrow \mathrm{Ca}\right.$ (тв. раствор) $+\mathrm{CaF}_{2}$, где $\mathrm{L}_{\text {eut }}-$ жидкость эвтектического состава). На равновесной диаграме состояния двойной эвтектической системы $\mathrm{Ca}-\mathrm{CaF}_{2}[71]$ реакция протекает при более высокой температуре, равной $828^{\circ} \mathrm{C}$. Наблюдаемое уменьшение температуры плавления металлических НЧ Са (или уменьшение температуры эвтектической реакции $\mathrm{L} \rightarrow \mathrm{Ca}\left(\right.$ тв. раствор) $\left.+\mathrm{CaF}_{2}\right)$ можно объяснить влиянием размерного фактора, так размер НЧ в образце S0 составляет $\sim 10-18 \mathrm{~nm}$ (см. выше данные ТЕМ анализа). Отметим, что нонвариантная эвтектическая реакция, во-первых, однозначно доказывает отклонение химического состава образца S0 от стехиометрического состава, во-вторых, согласуется с данными EDX анализа, который также показал сильное отклонение от стехиометрии в направлении кальциевого угла диаграммы состоянии $\mathrm{Ca}-\mathrm{CaF}_{2}$

Термический анализ отожженных образцов S200 и $\mathrm{S} 400$ (рис. 5, $b, c)$ показал:

(1) первый низкотемпературный эндотермический пик, присутствующий на кривых DSC образцов S0 и S200, связанный с адсорбированной наночастицами во- дой, постепенно уменьшался с увеличением температуры отжига и полностью исчез в образце S400 при температуре $400^{\circ} \mathrm{C}$ (см. кривую DSC на рис. 5, c);

(2) второй высокотемпературный эндотермический пик $\left(760-970^{\circ} \mathrm{C}\right)$ на кривой DSC неотожженного образца S0 (рис. 5,a), связанный с плавлением металлических частиц Са (либо с образованием жидкой фазы по эвтектической реакции $\mathrm{L} \rightarrow \mathrm{Ca}\left(\right.$ тв. раствор) $\left.+\mathrm{CaF}_{2}\right)$, отсутствует на обеих кривых DSC (рис. 5, $b, c$ ) образцов S200 и S400. Соответственно, на синхронных кривых TG образцов S200 и S400, отсутствуют участки, где наблюдался бы рост массы образца, как на участке III кривой TG образца S0. Отсутствие эндотермических пиков на кривых DSC и участков возрастания массы на кривых TG образцов S200 и S400 доказывает, что непродолжительный изотермический отжиг при температуре 200 и $400^{\circ} \mathrm{C}$ приводит к полному окислению металлических наночастиц Са в необлученном образце S0. Отметим наличие нового эндотермического пика в диапазоне температуры от 580 до $\sim 760^{\circ} \mathrm{C}$ на кривой DSC образца $\mathrm{S} 200$ (рис. 5, b). Наиболее вероятно, что данный эндотермический пик вызван реакцией разложения гидроксида кальция $\mathrm{Ca}(\mathrm{OH})_{2}$, который, в свою очередь, образовался в процессе изотермического отжига образца S200 при температуре $200^{\circ} \mathrm{C}$ в результате взаимодействии металлических наночастиц Са с парами воды, которые содержались в мезопорах исходного неотожженного образца 
S0. Температура разложения объемного $\mathrm{Ca}(\mathrm{OH})_{2}$ равна $580^{\circ} \mathrm{C}[72]$ совпадает с температурой начала появления вышеуказанного эндотермического пика на кривой DSC образца S200.

(3) Синхронные пики на масс-спектрах $\mathrm{H}_{2} \mathrm{O}$ и $\mathrm{CO}_{2}$ на термограмме образца S400 (рис. 5,c) подтверждают, что экзотермический пик в температурном диапазоне от 200 до $\sim 450^{\circ} \mathrm{C}$ на кривой DSC образца S400 связан с адсорбированным на поверхности наночастиц $\mathrm{CaF}_{2}$ углеродом. Хорошо известно [73], что с уменьшением размера наночастиц $\mathrm{CaF}_{2}$ адсобция диоксида углерода из окружающей атмосферы сильно возрастает и приводит к образованию карбоната и гидроксида кальция на поверхности наночастиц. Наиболее вероятным представляется образование гидроксида $\mathrm{Ca}(\mathrm{OH})_{2}$ и карбоната кальция $\mathrm{CaCO}_{3}$ в результате адсорбции молекул воды и молекул $\mathrm{CO}_{2}$ из мезопор нанопорошка и окружающего воздуха, соответственно, во время изотермического отжига при температуре $400^{\circ} \mathrm{C}$ образца S400. Поэтому, при дальнейшем динамическом нагревании отожженного образца S400 наблюдался обратный процесс разложения гидрооксида кальция по реакции $\mathrm{Ca}(\mathrm{OH})_{2} \rightarrow \mathrm{CaO}+\mathrm{H}_{2} \mathrm{O}$ и карбоната кальция по реакции $\mathrm{CaCO}_{3}=\mathrm{CaO}+\mathrm{CO}_{2}$, на что указывают соответствующие пики на массспектрах $\mathrm{H}_{2} \mathrm{O}$ и $\mathrm{CO}_{2}$ (рис. 5,c) при температуре около $300-325^{\circ} \mathrm{C}$. Реакции разложения относятся к эндотермическому типу, однако на кривой DSC на рис. 5, присутствует лишь слабый экзотермический пик. Наиболее вероятно, что поглощение тепла в реакции разложения гидроксида и карбоната кальция компенсируется выделением тепла при протекании экзотермической реакции кристаллизации аморфной фракции в НП $\mathrm{CaF}_{2}$. Окончательно, из образца $\mathrm{S} 400 \mathrm{CO}_{2}$ и вода удаляются лишь при высокой температуре около $700-750^{\circ} \mathrm{C}$, что подтверждают соответствующие пики на масс-спектрах $\mathrm{CO}_{2}$ и $\mathrm{H}_{2} \mathrm{O}$. Отметим, что $\mathrm{CO}_{2}$ - диамагнитный материал, поэтому присутствие $\mathrm{CO}_{2}$ не должно сильно влиять на магнитные свойства полученных методом PEBE наночастиц.

(4) На кривой TG образца S400 (рис. 5,c) убыль массы наблюдалась в трех температурных диапазонах: I - от 40 до $250^{\circ} \mathrm{C}$, II — от 250 до $525^{\circ} \mathrm{C}$ и III - от 525 до $1000^{\circ} \mathrm{C}$ и составила около 12.5 mass\%. Соответственно убыль массы образца S400 связана: в I диапазоне с испарением адсорбированной воды; во II диапазоне - с реакциями разложения гидрооксида $\mathrm{Ca}(\mathrm{OH})_{2} \mathrm{CaO}+\mathrm{H}_{2} \mathrm{O}$ и карбоната кальция $\mathrm{CaCO}_{3}=\mathrm{CaO}+\mathrm{CO}_{2}$ (также весьма вероятно протекание сопутствующей реакции карбонизации гидроокиси $2 \mathrm{Ca}(\mathrm{OH})_{2}+\mathrm{CO}_{2}=\mathrm{CaO}+\mathrm{CaCO}_{3}+2 \mathrm{H}_{2} \mathrm{O}$; в III диапазоне - c реакцией разложения карбоната кальция $\mathrm{CaCO}_{3} \rightarrow \mathrm{CaO}+\mathrm{CO}_{2}$. Основная потеря массы $\sim 3.5$ mass \% связана с трансформацией $\mathrm{Ca}(\mathrm{OH})_{2}$ в фазу $\mathrm{CaO}$. Отметим, что на синхронных кривых масс-спектров (рис. 5,c) присутствуют пики от паров воды и $\mathrm{CO}_{2}$, попадающие в температурные диапазоны II и III кривой TG, которые подтверждают образование конечных продуктов в результате протекания реакций разложения гидрооксида и карбоната кальция.

(5) Ha DSC кривой образца S400 (рис. 5,c) можно рассмотреть два слабых пика: эндотермический пик от испарения адсорбированной воды в температурном диапазоне от 40 до $250^{\circ} \mathrm{C}$ и экзотермический пик с максимумом при $325^{\circ} \mathrm{C}$. Экзотермический пик представляет собой суперпозицию одновременно протекающих реакций разного типа: разложения $\mathrm{Ca}(\mathrm{OH})_{2}$ (эндотермический тип), кристаллизация аморфной фракции (экзотермический тип), окисление возможных ядрооболочечных структур (ядро - $\mathrm{Ca}$; оболочка - $\mathrm{CaO}$ ) и других неидентифицированных реакций, например, реакции карбонизации (учитывая высокое содержание $\mathrm{CO}_{2}$ в исходном $\left.\mathrm{H \Pi} \mathrm{S} 0\right)$. В литературе сообщается, что реакция карбонизации происходит очень быстро для $\mathrm{Ca}(\mathrm{OH})_{2}$ и $\mathrm{CaO}[74]$, и скорость карбонизации увеличивается с увеличением удельной поверхности [74-76].

(6) Малая величина энтальпии экзотермического пика на кривой DSC образца S400 (рис. 5, c) показывает, что изотермический отжиг при температуре $400^{\circ} \mathrm{C}$ привел к отжигу большей части радиационных дефектов, что хорошо согласуется с литературными данными [49,77]. В свою очередь, относительно большая величина экзотермического пика на кривой DSC образца S200 (рис. $5, b$ ) свидетельствует, что удаление большей части воды из мезопор НП в процессе отжига при температуре $200^{\circ} \mathrm{C}$ способствует протеканию экзотермической реакции кристаллизации аморфной фракции НП и отжигу радиационных дефектов, который, по-видимому, также сопровождается выделением тепла.

Таким образом, термический анализ исходного S0 и отожженных образцов S200, S400 и S900 показал, что оптимальной температурой для отжига радиационных дефектов, образовавшихся в наночастицах $\mathrm{CaF}_{2}$ в процессе синтеза, и испарения большей части воды, адсорбированной на поверхности НЧ в процессах получения и хранения на воздухе, достаточно проведения отжига образцов при относительно низкой температуре, в диапазоне $400-450^{\circ} \mathrm{C}$. Отжиг при такой температуре не приводит к значительному росту размера НЧ или значительному увеличению концентрации кислорода в НЧ, что, в частности, согласуется с выводами авторитетных работ $[78,79]$ в которых показано, что отжиг фторидов $\mathrm{CaF}_{2}-\mathrm{Mn}$ (отжиг на воздухе при температуре $400^{\circ} \mathrm{C}$ в течении 2h) и $\mathrm{Sr}_{1-x-y} \operatorname{Pr}_{x} \mathrm{Yb}_{y} \mathrm{~F}_{2+x+y}$ (отжиг при температуре $600^{\circ} \mathrm{C}$ в течении $1 \mathrm{~h}$ ) не приводит к внедрению во фторид кальция следов кислорода и достаточен для надежного удаления всех следов кислот [78] и способствуют удалению воды и гидроксильных групп из фторида стронция [79]. Данные EDX анализа наших образцов S0 и S200 приведенные в табл. 3 подтверждают вышесказанное - при отжиге при температуре $200^{\circ} \mathrm{C}$ наблюдался лишь незначительный прирост концентрации кислорода. 
Таблица 4. Результаты деконволиции ФЛ спектров образцов до и после отжига

\begin{tabular}{|c|c|c|c|c|c|c|c|c|c|c|}
\hline Образец & $\mathrm{A}_{1}$, arb. units & $\lambda_{1}, \mathrm{~nm}$ & $\mathrm{FWHM}_{1}, \mathrm{~nm}$ & $\mathrm{~A}_{2}$, arb. units & $\lambda_{2}, \mathrm{~nm}$ & $\mathrm{FWHM}_{2}, \mathrm{~nm}$ & $\mathrm{~A}_{3}$, arb. units & $\lambda_{3}, \mathrm{~nm}$ & $\mathrm{FWHM}_{3}, \mathrm{~nm}$ & $\mathrm{~A}_{3} / \mathrm{A}_{2}\left(\mathrm{~A}_{2} / \mathrm{A}_{1}\right)$ \\
\hline \multicolumn{11}{|c|}{ ФЛ } \\
\hline S0 & - & - & - & 340634 & 650 & 50 & 389389 & 702 & 55.6 & 1.14 \\
\hline S200 & - & - & - & 255980 & 650 & 50 & 332402 & 701 & 57 & 1.3 \\
\hline S400 & 15827 & 581 & 78 & 14421 & 667 & 114 & & & & $(0.91)$ \\
\hline S900 & 962325 & 581 & 87 & 779963 & 681 & 93 & & & & $(0.81)$ \\
\hline
\end{tabular}

\section{8. Спектры ФЛ}

Фотолюминесценция (ФЛ) наноразмерного $\mathrm{CaF}_{2}$ изучалась ранее в [10,79-82]. Спектры ФЛ отличаются большим разнообразием и зависимостью от метода получения, концентрации дефектов и примесных элементов. В работе [10] спектры ФЛ наночастиц $\mathrm{CaF}_{2}$, синтезированных двумя методами (соосаждения и гидротермальный методы) показали серию полос излучения с максимумами при 328, 407, 470, 513 и $605 \mathrm{~nm}$ при возбуждении образцов при $\lambda_{\mathrm{ex}}=218 \mathrm{~nm}$. Наблюдаемое излучение при разных длинах волн объяснили наличием поверхностных дефектов Шоттки и Френкеля на поверхности наночастиц, а также примесью кислорода с вакансиями ионов фтора (примесная вакансия).

Нанокубы $\mathrm{CaF}_{2}$, полученные методом химического соосаждения [80], показали сильную эмиссионную полосу, локализованную при $\lambda=415 \mathrm{~nm}$ (длина волны возбуждения $325 \mathrm{~nm}$ ). Результаты [80] согласуются с результатами работы [10], в которой найден пик $\sim 407 \mathrm{~nm}$. В [10,80,81] показано, что образование примесных кислородных вакансий в нанокристаллической решетке $\mathrm{CaF}_{2}$ в процессе синтеза приводит к свечению. Спектр ФЛ пленок $\mathrm{CaF}_{2}$ (метод электроосаждения) при возбуждении $\lambda_{\mathrm{ex}}=297 \mathrm{~nm}$ показал широкую полосу в интервале 320-340 nm [28], что свидетельствует о большом количестве ловушек. Авторы [28] также связали люминесценцию пленок $\mathrm{CaF}_{2}$ с поверхностными дефектами типа Шоттки и Френкеля, вызванных высоким отношением объема к поверхности пленок.

$\mathrm{B}$ работе [81] получали нанокристаллический $\mathrm{CaF}_{2}$ (метод химического соосаждения), состоящий из смеси сферических и кубических структур размером от 20 до $80 \mathrm{~nm}$, которые показали широкую полосу ФЛ в диапазоне 370-550 nm. Авторы [81] объяснили появление широкой полосы образованием центров окраски, созданных с помощью кислородных дефектов в решетке $\mathrm{CaF}_{2}$. Известно, что кислородные дефекты (примеси) индуцируют эмиссионные полосы расположенные в длинноволновой области видимого спектра [82]. В работах $[81,82]$ уменьшение размера частиц до наношкалы приводило к реверсивному смещению эмиссионных полос в сторону коротких длин волн, благодаря уширению запретной полосы материала.

Хорошо известно, что агрегация точечных дефектов во фториде кальция под действием ионизирующе- го излучения приводит к образованию металлических наночастиц кальция, которые часто называют коллоидами [67-70]. Например, небольшие дозы электронов с энергией 2 кэВ приводят к образованию квазиорганизованных массивов из металлических наночастиц размером $20 \mathrm{~nm}$ в приповерхностной слое. Коллоидные наночастицы значительно снижают порог повреждения $\mathrm{CaF}_{2}$ при его использовании в литографии на $157 \mathrm{~nm}$ [70] и $193 \mathrm{~nm}$ [83]. Такие наночастицы сильно поглощают в диапазоне длин волн $>550 \mathrm{~nm}$, при этом спектр зависит от размера частиц [84]. Электронно-индуцированные наночастицы Са отбеливались лазерным излучением $(\lambda=157 \mathrm{~nm})$ при относительно низкой плотности потока в $10 \mathrm{~mJ} / \mathrm{cm}^{2}[82,83]$.

В работе [85] обнаружено, что концентрация радиационных дефектов, которые люминесцируют в оптической области спектра, увеличивалась при длительном воздействии электронного пучка. В ней наблюдали пик в запрещенной зоне при $2.5 \mathrm{eV}(496 \mathrm{~nm})$, соответствующий F-центру, и пик при $4.6 \mathrm{eV}(270 \mathrm{~nm})$, который отнесли к Н-центру. При более высоких уровнях электронного облучения происходило вытеснение фтора, и образование металлического Са, что определялось плотностью состояний металла и объемным плазмоном.

Спектры ФЛ образцов S0 и S200 $\mathrm{CaF}_{2}$ представляют собой широкие полосы с максимумами при $\lambda_{\text {max }} \sim 684 \mathrm{~nm}$ (рис. 6, $\left.a, b\right)$.

Отжиг образцов при $200^{\circ} \mathrm{C}$ не приводил к сдвигу $\lambda_{\max }$ при возбуждение полосы 320-380 nm. После отжига, интенсивность полосы образца S200 немного уменьшилась. В нашей ранней работе [86] мы связали люминесценцию образцов с F-центрами. После гауссовского разложения (табл. 4) появились две полосы, ответственные за два типа F-центров [87], с максимумами при $\sim 650$ и $\sim 702 \mathrm{~nm}$.

Наличие кислорода в образцах (табл. 3) указывает на его возможное участие в образовании F-центров со сложной структурой [81]. После отжига интенсивность ФЛ обоих F-центров уменьшалась в 1.3 и 1.2 раза, соответственно (табл. 3). Уменьшение интенсивности ФЛ указывает на небольшое уменьшение концентрации F-центров, по-видимому, из-за их частичной рекомбинации с возможными дырочными центрами типа $\mathrm{Vk}$, сформировавшимися во время испарения мишени $[88,89]$

Однако дальнейшее повышение температуры отжига привело к значительной трансформации ФЛ спектров отожженных образцов (рис. $6, c, d)$. 

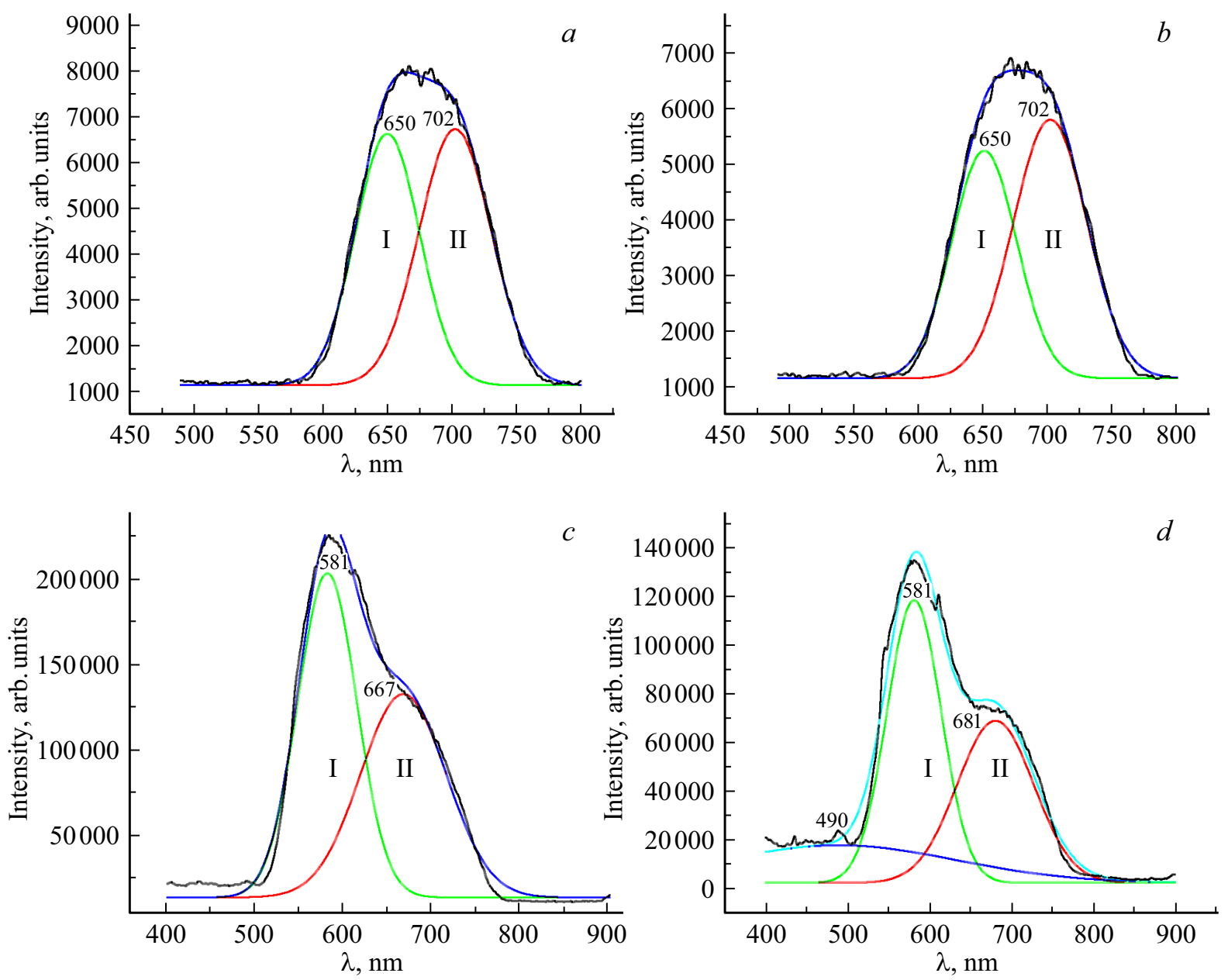

Рис. 6. Спектры ФЛ НЧ $\mathrm{CaF}_{2}$ до $(a)$ и после отжига на воздухе (время отжига составляло 10 min) при температуре $200^{\circ} \mathrm{C}(b)$, $400^{\circ} \mathrm{C}(c)$ и $900^{\circ} \mathrm{C}(d)$.

На обоих ФЛ спектрах образцов S400 и S900 исчезла длинноволновая полоса при $702 \mathrm{~nm}$, и появилась новая желтая полоса при $581 \mathrm{~nm}$. Отметим, что в натуральном фиолетовом флюорите широкая полоса поглощения наблюдалась всегда при длине волны $581 \mathrm{~nm}$ [90].

В фиолетовом аддитивно окрашенном (в парах Са при высокой температуре) синтетическом флюорите положение пика поглощения, связанного с коллоидными частицами $\mathrm{Ca}$, варьировалась в зависимости от увеличения размера частиц в диапазоне от (510-540) до $580 \mathrm{~nm}$ [91].

Также известно [92], что при воздействии электронного пучка в вакууме на кристалл $\mathrm{CaF}_{2}$ в области взаимодействия пучка с кристаллической решеткой кристалла сначала формируется аморфная фракция, которая при дальнейшем воздействии пучка приводит к образованию случайно ориентированных нанокристаллов оксида кальция $\mathrm{CaO}$. Эта аморфная фракция рассматривалась как гидроксид кальция, образовавшийся в результате реакции Са и воды, с учетом состава остаточного газа и скорости образования фракции.

В нашем случае, возможна подобная ситуация образования нанокристаллов $\mathrm{CaO}$ в результате кристаллизации аморфной фракции при отжиге (аморфная фракция присутствовала в образце $\mathrm{S} 0$ изначально и образовывалась в $\mathrm{HЧ}_{\mathrm{CaF}}$ в процессе их термической закалки в процессах абляции мишени и конденсации паров на холодной положке).

Исчезновение пика при $702 \mathrm{~nm}$ после отжига при температуре 400 и $900^{\circ} \mathrm{C}$ показывает, что данный эмиссионный пик связан с центром свечения, в котором, вероятнее всего, присутствовали металлические НЧ Са. Незначительное увеличение (12\%) отношения интенсивностей пиков I702/I650 при 702 и $650 \mathrm{~nm}$ с 1.14 до 1.28 было вызвано испарением при температуре $200^{\circ} \mathrm{C}$ адсорбированных на поверхности $\mathrm{HЧ} \mathrm{CaF}_{2}$ молекул воды, которые могли ослаблять фотолюминесценцию [93].

При более высокой температуре отжига $\left(400\right.$ и $\left.900^{\circ} \mathrm{C}\right)$ соотношение интенсивностей красной и желтой полосы изменилось $\left(I_{667} / I_{581}=0.91 ; I_{681} / I_{581}=0.81\right)$; доминирующей стала желтая полоса, а положение стабильного красного пика при $650 \mathrm{~nm}$ при этом изменилось в направлении длинноволновой области спектра, с 650 до $681 \mathrm{~nm}$. Подобное изменение положения пика поглощения наблюдали в работе [91], где положение пика 
Таблица 5. Результаты деконволюции спектров ИКЛ образцов S0-S900

\begin{tabular}{|c|c|c|c|c|c|c|c|c|c|c|}
\hline Образец & $\mathrm{A}_{1}$, arb. units & $\lambda_{1}, \mathrm{~nm}$ & $\mathrm{FWHM}_{1}, \mathrm{~nm}$ & $\mathrm{~A}_{2}$, arb. units & $\lambda_{2}, \mathrm{~nm}$ & $\mathrm{FWHM}_{2}, \mathrm{~nm}$ & $\mathrm{~A}_{3}$, arb. units & $\lambda_{3}, \mathrm{~nm}$ & $\mathrm{FWHM}_{3}, \mathrm{~nm}$ & $\mathrm{~A}_{3} / \mathrm{A}_{2}$ \\
\hline \multicolumn{11}{|c|}{ ИКЛ } \\
\hline Starget & 1331 & 502 & 48 & 1992 & 522 & 92 & - & - & - & \\
\hline S0 & 702 & 498 & 50 & 602 & 532 & 114 & 240 & 637 & 229 & 0.4 \\
\hline S200 & 1242 & 497 & 64 & 799 & 544 & 101 & 586 & 627 & 275 & 0.73 \\
\hline S400 & 1426 & 499 & 65 & 1360 & 524 & 164 & 503 & 678 & 230 & 0.37 \\
\hline S900 & 236 & 486 & 154 & 727 & 673 & 120 & 872 & 713 & 138 & 1.2 \\
\hline
\end{tabular}

поглощения, вызванного коллоидным Са, изменялось от 510-540 до $580 \mathrm{~nm}$ с увеличением размера частиц. В нашем случае изменение положения красного пика могло быть связано с ростом размера НЧ при отжиге и отчасти могло быть вызвано изменением фазового состава образцов в результате окисления НЧ металлического Са и вытеснения междоузельных ионов фтора из решетки $\mathrm{CaF}_{2}$ при высоких температурах отжига.

Отметим, что спектры ФЛ наночастиц $\mathrm{CaO}$, полученных золь-гель методом [92] и термическим разложением различных прекурсоров [93] содержали по три пика: при 340,430 и $475 \mathrm{~nm}$ и 350,395 и $490 \mathrm{~nm}$ соответственно. Небольшой пик при $490 \mathrm{~nm}$ присутствовал в спектре нашего образца S900 (рис. 6,d), что согласуется с данными работ $[92,93]$ и подтверждает образование НЧ $\mathrm{CaO}$ после отжига при температуре $900^{\circ} \mathrm{C}$.

Таким образом, мы наблюдали две новых полосы (702 и 650-686 nm) в красной области спектра $\mathrm{HЧ}^{\mathrm{CaF}_{2}}$, полученных при испарении РЕВЕ в форвакуумных условиях. Данное излучение могло возникнуть в сложных центрах, которые сформировались в сильно неравновесных условиях при испарении и конденсации НЧ. Очевидно, что в наших образцах $\mathrm{CaF}_{2}$ в эволюции пиков с ростом температуры отжига принимали участие три различных типа эмиссионных центров, которые были связаны с металлическими НЧ Са и НЧ $\mathrm{CaO}$ (702 и $581 \mathrm{~nm}$ соответственно) и с одним из многих комплексных центров $(650-680 \mathrm{~nm})$, который непрерывно трансформировался при повышении температуры отжига, что отражалось на изменении его длине волны.

Насколько нам известно, о подобной ФЛ в красной области спектра в щелочноземельных фторидах почти нет сообщений, за исключением люминесценции фторидов бария при $626.5 \mathrm{~nm}$ в работе [87] и кальция (соprecipitation method) при $794 \mathrm{~nm}$ [94]

\section{4. Спектры ИКЛ}

На рис. 7 приведены ИКЛ спектры (в видимой и ультрафиолетовой областях спектра) мишени и образцов S0, S200, S400 и S900.

Спектры катодолюминесценции наночастиц $\mathrm{CaF}_{2}$ описаны в работах $[37,95,96]$. Ранние исследования [95] показали, что спектр КЛ и его температурная зависимость для кристаллов $\mathrm{CaF}_{2}$, возбужденных низкоэнергетическими электронами $(10 \mathrm{keV}, 20 \mu \mathrm{A})$, во многом схожи со спектром люминесценции, полученным рентгеновским облучением, за исключением небольших различий в относительных интенсивностях некоторых областей эмиссии. Обычно, эмиссия в ультрафиолетовой области спектра (UV) сильнее эмиссии в видимой области спектра (VIS) для всех температур возбуждения от 28 до $250^{\circ} \mathrm{C}$; при этом относительная интенсивность в VIS выше при рентгеновском возбуждении. В работе [58] экспериментально показано, что облучение кристаллов $\mathrm{MgF}_{2}, \mathrm{CaF}_{2}$ и $\mathrm{BaF}_{2}$ электронами с энергией $50-70 \mathrm{keV}$ (сопоставимой с энергией электронов на установке Нанобим-2, равной $40 \mathrm{keV}$ ) приводит к локальному образованию в приповерхностном слое металлических наночастиц $\mathrm{Mg}$, $\mathrm{Ca}$ or $\mathrm{Ba}$, которые показывают плазмонный резонанс. Отмечено [58], что электронное облучение кристаллов $\mathrm{MgF}_{2}$ привело к увеличению поглощения и к появлению люминесценции в VIS диапазоне; широкая люминесцентная полоса появилась в диапазоне от 500 до $700 \mathrm{~nm}$ с максимумом при $570 \mathrm{~nm}$. КЛ $\mathrm{CaF}_{2}$ в VIS области спектра была очень слабой, в отличие от $\mathrm{MgF}_{2}$.

В работе [96] были исследованы катодолюминесцентные свойства натурального белого флюорита (возбуждение $25 \mathrm{keV}$ электронным пучком). Образец минерала показал значительную ультрафиолетовую эмиссию, связанную с различными структурными дефектами (незначительными в синтетическом образе $\mathrm{Mn}$-doped $\mathrm{CaF}_{2}$ ) и сдвиг зеленого излучения в сторону более высоких длин волн по отношению к TLD-400 (природный флюорит продемонстрировал два пика излучения при 300 и $562 \mathrm{~nm}$, тогда как $\mathrm{CaF}_{2}: \mathrm{Mn}$ показал один максимум центрированный при $490 \mathrm{~nm}$ ).

Спектры ИКЛ образцов S0-S900, приведенные на рис. 7 (за исключением образца S900), представляют собой ассиметричные широкие полосы протяженностью от 350 до $800 \mathrm{~nm} \mathrm{с} \mathrm{максимумами} \mathrm{при} \sim 500 \mathrm{~nm}$. Деконволюция спектра образца мишени с помощью двух гауссианов, показала наличие двух зеленых пиков с максимумами при 502 и $521 \mathrm{~nm}$ (рис. 7,b). Спектр мишени из субмикронного порошка показал максимальную интенсивность. Правое плечо спектра ограничено длиной волны около $675 \mathrm{~nm}$. С увеличением температуры отжига интенсивность эмиссии образцов монотонно 

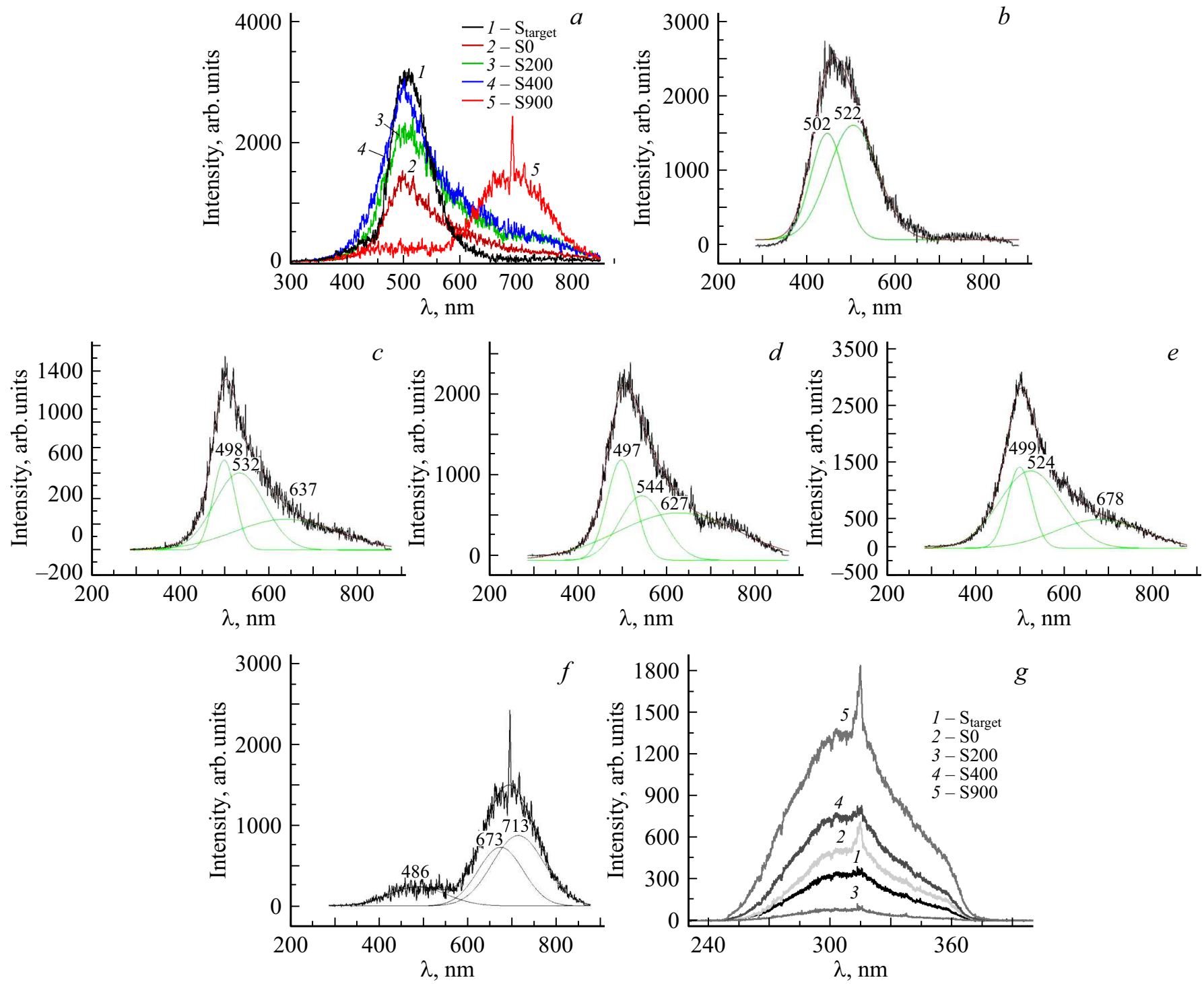

Рис. 7. а) Спектры ИКЛ (видимая область ) мишени (1) и образцов S0 (2), S200 (3), S400 (4) и S900 (5), записанные при комнатной температуре; деконволюция спектров ИКЛ мишени $(b)$ и образцов $\mathrm{S} 0(c), \mathrm{S} 200(d), \mathrm{S} 400(e)$ и S900 (f); $g$ - спектры ИКЛ мишени (1) и образцов S0 (2), S200 (3), S400 (4) и S900 (5) в ультрафиолетовой области спектра.

нарастала. Интенсивность эмиссии образца S400 сопоставима с интенсивностью свечения мишени.

Деконволюция спектров ИКЛ образцов S0-S900 (рис. 7, $c-f)$ выполнялась с помощью трех гауссианов. Результаты деконволюции показаны на рис. $7, c-f$ и в табл. 5.

ИКЛ спектры образцов S0-S400 состоят из трех пиков: двух зеленых пиков с максимумами при 498 и (524-544) nm и красного пика при (627-678) nm. Положение красного пика при $498 \mathrm{~nm}$ не изменяется при отжиге, у остальных пиков положение изменяется немонотонно.

Спектр образца S900 сильно отличается от спектров остальных образцов. Широкая полоса с максимумом при $500 \mathrm{~nm}$ практически исчезла. Спектр состоит из двух красных и одного голубого пика с максимумами при 713, 673 и $486 \mathrm{~nm}$ соответственно. Острый пик при $693.4 \mathrm{~nm}$ отвечает R-линии примесных ионов $\mathrm{Cr}^{3+}$ в результате диффузии ионов из алундового тигля, в котором проводился отжиг. Появление широкой доминантной красной полосы при $713 \mathrm{~nm}$ указывает на образование нового оптического центра в образце S900 в результате отжига. Вероятно, появление нового центра эмиссии также связано и с фазовой трансформацией однофазного $\mathrm{CaF}_{2}$ в двухфазный образец, содержащий фазу $\mathrm{CaO}$. Фаза $\mathrm{CaO}$ образуется при отжиге $\mathrm{CaF}_{2}$ на воздухе на поверхности НЧ, поэтому обнаружить фазу $\mathrm{CaO}$ с помощью РФА или ПЭМ достаточно сложно [97]. Тем не менее, данные EDX анализа показали увеличение концентрации кислорода в образце S200 почти в 2 раза (табл. 3) по сравнению с образцом S0, даже при столь коротком (10 $\mathrm{min})$ отжиге. 
Спектры ИКЛ неотожженного и отожженных образцов (рис. $7, g$ ) в УФ области спектра схожи между собой. Они представляют собой широкую, ассиметричную полосу в диапазоне длин волн от 250 до $375 \mathrm{~nm}$ с пиком при $\sim 300 \mathrm{~nm}$. Деконволюция с помощью двух гауссианов показала, что спектры состоят из двух взаимно пересекающихся полос, с пиками, центрированными при 305 и $350 \mathrm{~nm}$. Доминантный широкий пик при $305 \mathrm{~nm}$ качественно согласуется со спектром люминесценции связанных экситонов (STE), приведенном во многих работах $[98,99]$. Второй пик м.быть связан с поверхностными дефектами типа Френкеля. Подобные спектры были получены в [95] при облучении $\mathrm{CaF}_{2}$ низкоэнергетическими электронами $(10 \mathrm{keV}, 20 \mu \mathrm{A})$ при комнатной температуре.

Кристаллы $\mathrm{CaF}_{2}$ показали две широкие полосы в УФ и видимой частях спектра, с двумя ярко выраженными максимумами при 280 и $310 \mathrm{~nm}$. Отжиг образцов усиливает STE люминесценцию, что согласуется с результатами многих работ [100], где показано, что после отжига облученных электронами образцов $\mathrm{CaF}_{2}$ наблюдается дополнительное увеличение интенсивности свечения.

Однако наиболее важным моментом является наличие двух вышеуказанных пиков, как в диамагнитном образцемишени, так и в магнитных $\mathrm{HП} \mathrm{CaF}_{2}$ (рис. $7, g$ ), следовательно, ФМ свойства НП $\mathrm{CaF}_{2}$ никак не связаны с STE экситонами и поверхностными дефектами Френкеля.

\section{1. Рамановские спектры}

На рис. 8 представлены рамановские спектры для образцов $\mathrm{CaF}_{2}$ до и после отжига. В спектре записаном после отжига при $200^{\circ} \mathrm{C}-$ появились новые линии при 193 и $606 \mathrm{~cm}^{-1}$. Интенсивности линий при 716, 748 и $773 \mathrm{~cm}^{-1}$ увеличились после отжига. Большинство линий соответствуют значениям таковых для $\mathrm{CaF}_{2}$, рамановский спектр которого приведен в работе [101]. Наличие дополнительных линий в спектре указывает на увеличение числа различных дефектов в наночастицах $\mathrm{CaF}_{2}$ после отжига. Известно, что искажение фононного спектра кристаллов дефектами приводит к появлению дополнительных частот в спектрах комбинационного рассеяния [102]. Изменение интенсивности в спектрах комбинационного рассеяния из-за наличия различных концентраций точечных дефектов и коллоидов $\mathrm{Ca}$, которые появились в $\mathrm{CaF}_{2}$, после облучения ионами $\mathrm{Au}$ $2.2 \mathrm{GeV}$, наблюдали также в [103]

\subsection{Magnetic properties}

На рис. 9 приведены кривые удельной намагниченности при комнатной температуре образцов НП S0S900 и микронного порошка Starget. Микронные частицы показали диамагнитный отклик при комнатной температуре (кривая $S_{\text {target }}$ на рис. 9), поэтому люминесцентные центры, связанные с пиками эмиссии при 502 и $522 \mathrm{~nm}$

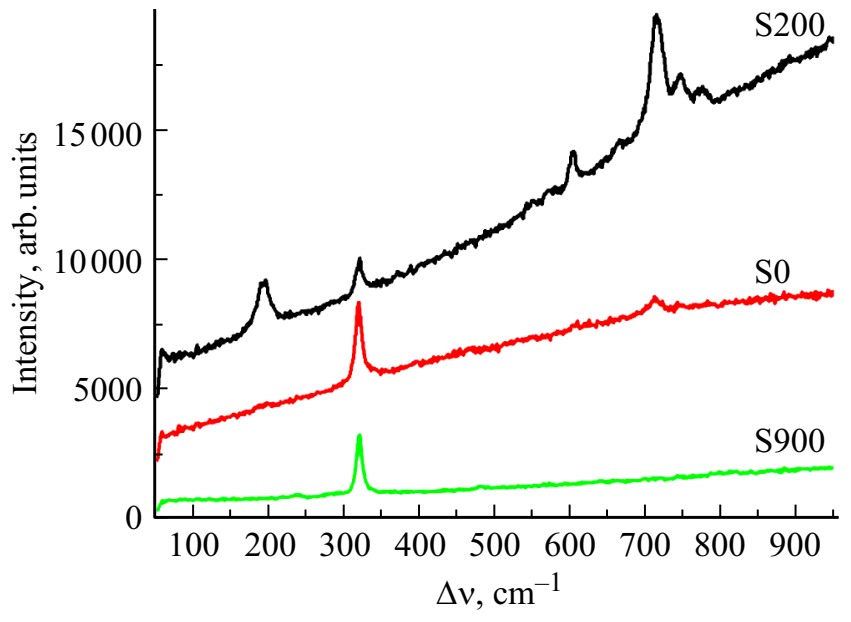

Рис. 8. Рамановские спектры образцов S0, S200 и S900.

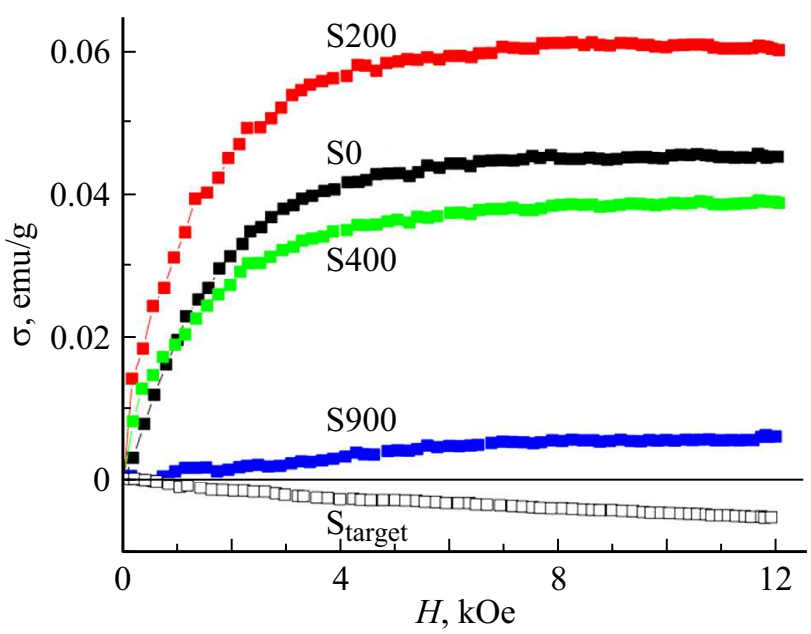

Рис. 9. Кривые удельной намагниченности при комнатной температуре: мишени $(a)$ и образцов $\mathrm{S} 0(b), \mathrm{S} 200(c), \mathrm{S} 400(d)$ и $\mathrm{S} 900(e)$.

в образце $S_{\text {target }}$ (рис. $\left.7, b\right)$ не отвечают за появление $\Phi \mathrm{M}$ отклика в образцах наночастиц $\mathrm{S} 0-\mathrm{S} 900$.

Все образцы НП показали ФМКТ (рис. 9).

После перехода в наносостояние в образцах $\mathrm{S} 0-\mathrm{S} 900$ (рис. 9, кривые $\mathrm{S} 0-\mathrm{S} 900$ ) появился ферромагнитный вклад, который менялся при последующих отжигах немонотонным образом: слегка увеличивался после отжига при $200^{\circ} \mathrm{C}$, затем начинал снижаться (отжиг при $400^{\circ} \mathrm{C}$ ) и резко падал после отжига при $900^{\circ} \mathrm{C}$.

Появление ФМ отклика в наноразмерном $\mathrm{CaF}_{2}$ можно объяснить формированием структурных и радиационных дефектов в процессе синтеза НЧ. В массивном состоянии в кристаллах $\mathrm{CaF}_{2}$ ионы кальция и фтора не обладают магнитным моментом, поскольку их электронные оболочки заполнены. Попытки объяснить ФМКТ в подобных веществах в наносостоянии (так называемый , $d^{0}$ магнетизм“ $)$ предприняты в целом ряде работ $[104,105]$. Опираясь на развитые в этих рабо- 
тах представления $\Phi \mathrm{M}$ отклика в наноразмерном $\mathrm{CaF}_{2}$ можно связать с формированием структурных и радиационных дефектов в процессе синтеза НЧ. Основной особенностью НП, полученых методом РЕВЕ, является образование в них большого количества структурных дефектов различных типа [43]. Также дефекты образуются под воздействием тормозного рентгеновского излучения при синтезе НП. Поэтому, по аналогии с моделью [106], можно предположить, что вакансии фтора могли участвовать в формировании FM в образцах.

Наша гипотеза представляла собой попытку объяснить магнитное поведение образцов через корреляцию спектров ИКЛ и ФЛ с удельной намагниченностью образцов.

В ИКЛ спектрах образцов S0-S900, показавших в той или иной степени ФМ отклик, всегда присутствовал только один красный пик, локализованный в диапазоне длин волн $\sim 627-678 \mathrm{~nm}$, в то же время, в диамагнитном образце микронного размера $\left(S_{\text {target }}\right)$ данный красный пик отсутствовал. Красный пик при $650-686 \mathrm{~nm}$, также присутствовал в ФЛ спектрах всех магнитных образцов НЧ (рис. 6). Другой, менее интенсивный длинноволновый красный пик, присутствовал в люминесцентных спектрах отдельных образцов: в ИКЛ спектре образца S900 (рис. 7,f) при $713 \mathrm{~nm}$, и ФЛ спектрах образцов S0 и S200 (рис. 6, $a, b$ ) при 702 и $701 \mathrm{~nm}$ соответственно; в спектрах остальных образцов красный пик отсутствовал. Поэтому маловероятно, чтобы появление ФМ отклика в наноразмерных образцах было связано с дефектными эмиссионными центрами, ответсвенными за эмиссию красной полосы при $702-713 \mathrm{~nm}$.

Намагниченность $\mathrm{HЧ} \mathrm{CaF}_{2}$ прямо связана с дефектами (центрами люминесценции) ответсвенными за ИКЛ красной полосы при (627-678) nm и ФЛ красной полосы при (650-681) nm, так как вышеуказанные полосы присутствуют в ИКЛ и ФЛ спектрах всех магнитных образцов, и отсутствуют в спектрах немагнитных образцов мишеней. Отметим также корреляцию удельной поверхности НЧ с магнитными и спектральными характеристиками образцов S200-S900. Корреляция температурных зависимостей магнитных $\left(\sigma-T_{a}\right), \quad$ текстурных $\left(\mathrm{SSA}-T_{a}\right)$, фотолюминесцентных $\left(I_{\mathrm{PL}}(702) / I_{\mathrm{PL}}(650)-T_{a} ; I_{\mathrm{PL}}(667,681) / I_{\mathrm{PL}}(581)-T_{a}\right)$

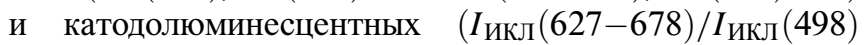
свойств $\mathrm{HЧ}_{\mathrm{CaF}}$, нормированных на единицу, показана на рис. 10.

Центры эмиссии ИКЛ в УФ спектре никак не связаны с магнитными свойствами $\mathrm{HЧ} \mathrm{CaF}_{2}$, так как такие эмиссионные пики присутствуют в УФ спектре диамагнитного образца мишени $S_{\text {target }}$ (рис. $7, g$ ).

Одной из важнейших характеристик магнитного материала является его температурная зависимость намагниченности. Такая зависимость часто позволяет идентифицировать небольшие ферромагнитные примеси в немагнитных средах. На рис. 11 приведены температурные кривые намагниченности образца S200 в области 1 T и магнетита [107].

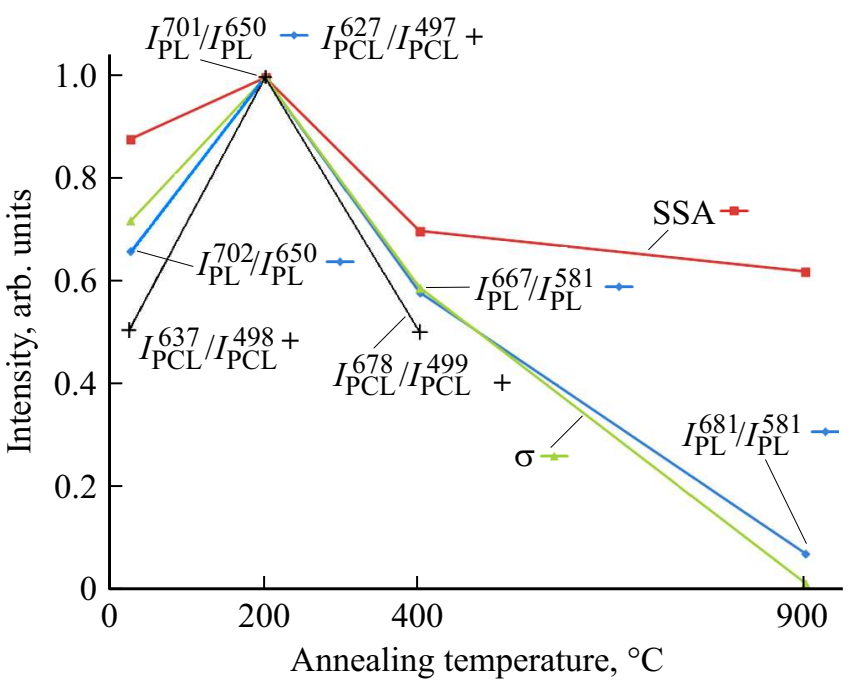

Рис. 10. Корреляция нормированных на единицу температурных зависимостей магнитных $\left(\sigma-T_{a}\right)$, текстурных $\left(\mathrm{SSA}-T_{a}\right), \quad$ фотолюминесцентных $\quad\left(\mathrm{IPL}(702) / \operatorname{IPL}(650)-T_{a}\right.$; $\left.\operatorname{IPL}(667,681) / \operatorname{IPL}(581)-T_{a}\right) \quad$ и $\quad$ катодолюминесцентных (ІИКЛ(627-678)/ІИКЛ(498) $\quad$ свойств $\quad$ НЧ $\quad \mathrm{CaF}_{2} . \quad T_{a}$ температура отжига.
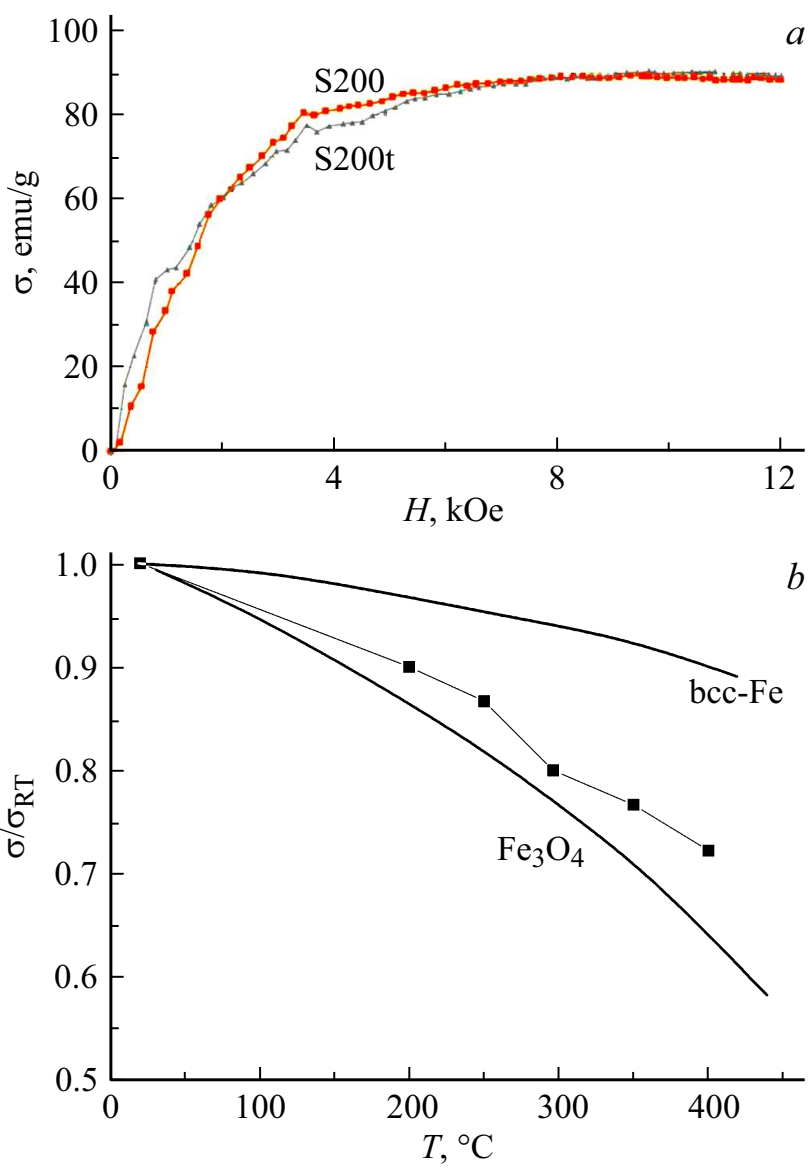

Рис. 11. а) Кривые намагничивания образца S200 перед отжигом в атмосфере аргона и после отжига (кривая с индексом „t“); b) Зависимость намагниченности образцов $\mathrm{S} 200, \mathrm{Fe}_{3} \mathrm{O}_{4}$ и $b c c$-Fe от температуры. 
Видно, что природа температурной зависимости намагниченности $\mathrm{CaF}_{2}$ отличается таковой для $\mathrm{Fe}_{3} \mathrm{O}_{4}$. Очевидно, что металлическое железо также не могло сыграть роль магнитной примеси, потому что температурная зависимость намагниченности железа также существенно отличается от измеренной. Кроме того, отжиг в $200^{\circ} \mathrm{C}$ в воздухе не мог увеличить намагниченность частиц, предполагая их присутствие в образец. Нагрев образца S200 в бескислородной атмосфере до температуры $400^{\circ} \mathrm{C}$ не привел к изменению его магнитных свойств (рис. 11,a). Таким образом, согласно представленным экспериментальным данным, примесная природа ФМКТ $\mathrm{CaF}_{2} \mathrm{HЧ}$ маловероятна.

\section{5. Заключение}

Мезопористый нанокристаллический порошок фторида кальция синтезирован с помощью метода импульсного электронного испарения в вакууме.

Исследовано влияние изотермического отжига на воздухе в температурном диапазоне $200-900^{\circ} \mathrm{C}$ на структуру, текстурные, термические, люминесцентные и магнитные свойства нанопорошка $\mathrm{CaF}_{2}$. Результаты показали успешное образование флюоритной решетки $\mathrm{CaF}_{2}$ в форвакуумных условиях.

Диамагнитный в объемном состоянии $\mathrm{CaF}_{2}$ после трансформации в наноразмерное состояние приобрел ферромагнитные свойства при комнатной температуре. Ферромагнитные $\mathrm{HЧ} \mathrm{CaF}_{2}$ после отжига при температуре в $900^{\circ}$ вернулись обратно, в исходное диамагнитное состояние.

Установлена корреляция между зависимостями $I_{\mathrm{PL}}(702) / I_{\mathrm{PL}}(650)-T_{a} ; \quad I_{\mathrm{PL}}(667,681) / I_{\mathrm{PL}}(581)-T_{a}$, $I_{\text {ИкЛ }}(627-678) / I_{\text {ИкЛ }}(498)$, Ууд $-T_{a}$ и $\sigma-T_{a}$.

Микроскопические исследования показали образование квазисферических $\mathrm{HЧ} \mathrm{CaF}_{2}$ размером около 10-20 nm. Элементное картирование показало отсутствие возможных металлических кластеров Са и гомогенное распределение элементов в образцах, включая примеси улерода и кислорода.

Нанопорошок $\mathrm{CaF}_{2}$ содержал высокий объем межчастичных пор (до $0.66 \mathrm{~cm}^{3} / \mathrm{g}$ ), что делает его привлекательным для использования в качестве наноконтейнера в биомедицине.

Совокупность полученных экспериментальных данных (РФА, электронография, микроскопия, элементное картирование, изменение соотношения интегральных интенсивностей $\left(I_{\text {green }} / I_{\text {red }}\right)$ в спектрах ИКЛ, термический анализ) доказывает, что ФМКТ наночастиц $\mathrm{CaF}_{2}$ является их внутренним свойством и не вызван посторонними магнитными примесями $3 d$ металлов и т. П.

Вероятно, что за появление ФМКТ в наночастицах $\mathrm{CaF}_{2}$ отвечают сложные, комплексные дефекты, которые трансформируются при отжиге и вызывают смещение красных пиков в спектрах ФЛ и ИКЛ в длинноволновую область спектра. В образовании магнитных дефектов (наиболее вероятно) вовлечены вакансии фтора и вакансии примесного кислорода, а также междоузельные ионы фтора.

DSC-TG анализ подтвердил наличие металлических НЧ $\mathrm{Ca}$ в НП $\mathrm{CaF}_{2}$, синтезированном в условиях ваккума. Образование НЧ $\mathrm{CaO}$ при отжиге подтверждено методами ФЛ и ИКЛ.

\section{Благодарности}

Авторы признательны С.В. Пряничникову за рентгенофазовый анализ, T.M. Деминой за текстурный и DSC-TGанализ, А.В. Спириной за запись и обсуждение спектров импульсной катодолюминесценции, Э.Г. Вовкотруб за получение Raman спектров. РФА выполнен в центре коллективного пользования „Урал-М“ ИМЕТ УрО РАН.

\section{Финансирование}

Работа выполнена в рамках проекта государственного задания № 0389-2015-0026, поддержаного грантом РФФИ № 18-08-00514. Это исследование было поддержано финансированием институционных исследований (IUT224 и IUT20-54) и проектом Namur+Министерства образования и науки Эстонской Республики. Магнитные измерения проводились в рамках государственного задания - тема „Магнит“ № АААА-А18-118020290129-5.

\section{Конфликт интересов}

Авторы заявляют, что у них нет конфликта интересов.

\section{Список литературы}

[1] P.P. Fedorov, S.V. Kuznetsov, V.V. Osiko.Elaboration of Nanofluorides and Ceramics for Optical and Laser Applications. In: Photonic and Electronic Properties of Fluoride Materials: Progress in Fluorine Science Series (2016) P. 7.

[2] N. Sholina, P. Demina, D. Khochenkov, A. Generalova, A. Nechaev, E. Khaydukov. EPJ Web Conferences 190, 26 (2018).

[3] J. Lellouche, A. Friedman, A. Gedanken, E. Banin. Int. J. Nanomed. 7, 5611 (2012).

[4] V.S. Kortov. Rad. Meas. 45, 512 (2012).

[5] S.V. Kuznetsov, O.A. Morozov, V.G. Gorieva, M.N. Mayakova, M.A. Marisov, V.V. Voronov, A.D. Yapryntsev, V.K. Ivanov, A.S. Nizamutdinov, V.V. Semashko, P.P. Fedorov. J. Fluorine Chem. 211, 70 (2018).

[6] X. Sun, Y. Li. Chem. Commun. 0, 1768 (2003).

[7] Z. Li, Y. Zhang, L. Huang, Y. Yang, Y. Zhao, G. El-Banna, G. Han. Theranostics. 6, 2380 (2016).

[8] M.S. Akchurin, T.T. Basiev, A.A. Demidenko, M.E. Doroshenko, P.P. Fedorov, E.A. Garibin, P.E. Gusev, S.V. Kuznetsov, M.A. Krutov, I.A. Mironov, V.V. Osiko, P.A. Popov. Opt. Mater. 35, 444 (2013).

[9] X. Zhang, Z. Quan, J. Yang, P. Yang, H. Lian, J. Lin. J. Nanotechnology 19, 075603 (2008). 
[10] C. Pandurangappa, B.N. Lakshminarasappa, B.M. Nagabhushana. J. Alloys Compd. 489, 592 (2010).

[11] P.T. Patil, A. Dimitrov, J. Radnik, E. Kemnitz. J. Mater. Chem. 18, 1632 (2008).

[12] A. Bensalah, M. Mortier, G. Patriarche, P. Gredin, D. Vivien. J. Solid State Chem. 179, 2636 (2006).

[13] A. Safronikhin, H. Ehrlich, G. Lisichkin. J. Alloys Compd. 694, 1182 (2017).

[14] L. Sun, L.C. Chow. Dent. Mater. 24, 111 (2008).

[15] L. Ma, L.L. Yang, Y.G. Wang, X.P. Zhou, X.Y. Xu. Ceram. Int., 39, 5973 (2013).

[16] R. Witter, M. Roming, C. Feldmann, A.S. Ulrich. J. Colloid Interface Sci. 390, 250 (2013).

[17] M. Dreger, G. Scholz, E. Kemnitz. Solid State Sci. 14, 528 (2012).

[18] R.N. Grass, W.J. Stark. Chem. Commun. 0, 1767 (2005).

[19] A. Astruc, C. Cochon, S. Dessources, S. Célérier, S. Brunet. Appl. Catal. A. 453, 20 (2013).

[20] В.В. Осипов, В.В. Лисенков, В.В. Платонов, Е.В. Тихонов. Квантовая электроника 48, 235 (2018).

[21] P. Dolcet, A. Mambrini, M. Pedroni, A. Speghini, S. Gialanella, M. Casarina, S. Gross. RSC Adv. 5, 16302 (2015).

[22] H. Kim, A.H. King. J. Mat. Res. 22, 2012 (2007).

[23] R.F.C. Farrow, P.W. Sullivan, G.M. Williams, G.R. Jones, D.C. Cameron. J. Vac. Sci. Technol. 19, 415 (1981).

[24] A. De Bonis, A. Santagata, A. Galasso, M. Sansone, R. Teghil. Appl. Surf. Sci. 302, 145 (2014).

[25] A. Klust, R. Kayser, J. Wollschlager. Phys. Rev. B. 62, 2158 (2000).

[26] M. Ylilammi, T. Rantaaho. J. Electrochem. Soc. 141, 1278 (1994).

[27] A.V. Blednov, O.Y. Gorbenko, S.V. Samoilenkov, V.A. Amelichev, V.A. Lebedev, K.S. Napolskii, A.R. Kaul. Chem. Mater. 22, 175 (2010).

[28] H. Wang, R. Liu, K. Chen, X. Shi, Z. Xu. Thin Solid Films 519, 6438 (2011).

[29] R.D. Shannon. Acta Crystallogr. Sect. A. 32, 751 (1976).

[30] P.D. Belsare, C.P. Joshi, S.V. Moharil, S.K. Omanwar, P.L. Muthal, S.M. Dhopte. Opt. Mater. 31, 668 (2009).

[31] S.Yu. Sokovnin, V.G. Il'ves, M.G. Zuev, M.A. Uimin. J. Phys: Conf. Ser. 1115, 032092 (2018).

[32] A. Lushchik, C. Lushchik, E. Vasil'chenko, A.I. Popov. Low Temp. Phys. 44, 269 (2018).

[33] A.E. Angervaks, A.V. Veniaminov, M.V. Stolyarchuk, V.E. Vasilev, I. Kudryavtseva, P.P. Fedorov, A.I. Ryskin. J. Opt. Soc. America B: Opt. Phys. 35, 1288 (2018).

[34] А.С. Щеулин, Т.С. Семенова, Л.Ф. Корякина, М.А. Петрова, А.Е. Ангервакс, А.И. Рыскин. Оптика и спектроскопия 110, 660 (2011).

[35] A.I. Ryskin, N.T. Bagraev, A. Lushchik, E. Shablonin, I. Kudryavtseva, A.E. Angervaks. Solid State Ionics 323, 136 (2018).

[36] A.I. Ryskin, P.P. Fedorov, N.T. Bagraev, A. Lushchik, A.E. Angervaks, I. Kudryavtseva. J. Fluorine Chem. 200, 109 (2017).

[37] R. Assylbayev, A. Lushchik, Ch. Lushchik, I. Kudryavtseva, E. Shablonin, E. Vasil'chenko, A. Akilbekov, M. Zdorovets. Opt. Mater. 75, 196 (2018).

[38] C.S. Bezerran, M.E.G. Valerio. Physica B 501, 106 (2016).
[39] S.V. Kuznetsov, O.A. Morozov, V.G. Gorieva, M.N. Mayakova, M.A. Marisov, V.V. Voronov, A.D. Yapryntsev, V.K. Ivanov, A.S. Nizamutdinov, V.V. Semashko, P.P. Fedorov. J. Fluorine Chem. 211, 70 (2018).

[40] M. Straßer, J.H.X. Schrauth, S. Dembski, D. Haddad, B. Ahrens, S. Schweizer, B. Christ, A. Cubukova, M. Metzger, H. Walles, P.M. Jakob, G. Sext. Beilstein J. Nanotech. 8, 1484 (2017).

[41] N. Kumar. Thesis. Master of Science. Jawaharlal Nehru Centre for Advanced Scientific Research (A Deemed University) Bangalore, India (2010).

[42] S.Yu. Sokovnin, V.G. Il'ves. Ferroelectrics 436, 101 (2012).

[43] S.Y. Sokovnin, V.G. Il'ves, M.G. Zuev. In: Engineering of Nanobiomaterials: Applications of Nanobiomaterials. Ed. A.M. Grumezesab. Vol. 2. Elsevier Inc.,Amsterdam, P. 29.

[44] С.Г. Михайлов, В.В. Осипов, В.И. Соломонов. Приборы и техника эксперимента 44, 164 (2001).

[45] A. Smakula. Phys. Rev. 77, 408 (1949).

[46] W. Bontinck. Physica 24, 639 (1958).

[47] M. Izerrouken, L. Guerbous, A. Meftah. Nucl. Instrum. Methods A 621, 68 (2010).

[48] I. Nicoara, M. Stef, D. Vizman, C.D. Negut. Radiat. Phys. Chem. 153, 70 (2018).

[49] M. Izerrouken, A. Meftah, M. Nekkab. J. Lumin. 127, 696 (2007).

[50] F.K. Fong, P.N. Yocom. J. Chem. Phys. 41, 1383 (1964).

[51] W.J. Scouler, A. Smakula. Phys. Rev. 120, 1154 (1960).

[52] V. Ausin, J.L. Alvarez Rivas. Phys. Rev. B. 9, 775 (1974).

[53] N.O. Dantas, S. Watanabe, J.F.D. Chubaci. Nucl. Instrum. Methods B 116, 269 (1996).

[54] C. Florea, M. Zamfires, F. Jipa, A. Velea. J. Intense Pulsed Laser Appl. Adv. Phys. 1, 1 (2011).

[55] R. Assylbayev, A. Akilbekov, A. Dauletbekova, A. Lushchik, E. Shablonin, E. Vasil'chenko. Rad. Meas. 90, 18 (2016).

[56] S.L. Baldochi, I.M. Ranieri. Acta Phys. Pol. A 124, 286 (2013).

[57] S.D. McLaughlan, H.W. Evans. Crystals Phys. Status Solidi 27, 695 (1968)

[58] E.S. Bochkareva, A.I. Sidorov, U.V. Yurina, O.A. Podsvirov. Nucl. Instrum. Methods Phys. Res., Sect. B. 403, 1 (2017).

[59] AEROSIL $囚-$ Fumed Silica Technical Overview; https://www.aerosil.com/sites/lists/RE/DocumentsSI/TechnicalOverview-AEROSIL-Fumed-Silica-EN.pdf

[60] С.Ю. Соковнин, В.Г. Ильвес, М.Г. Зуев, М.А. Уймин. Письма в ЖТФ 44, 19 (2018).

[61] A. Astruc, C. Cochon, S. Dessources, S. C'el'erier, S. Brunet. Appl. Catal. A 453, 20 (2013).

[62] S.Y. Arkhipenko, A.A. Fedorova, I.V. Morozov, A.S. Shaporev. Mendeleev Commun. 22, 25 (2012).

[63] T.Yu. Glazunova, A.I. Boltalin, P.P. Fedorov. Rus. J. Inorg. Chem. 51, 983 (2006).

[64] H. Kim, A.H. King. J. Mat. Res. 22, 2012 (2007).

[65] И.Г. Рысс. Химия фтора и его неорганических соединений. Госхимиздат, М. (1966), 718 с.

[66] Л.Р. Бацанова, Н.В. Подберезская. Журн. неорган. химии 11, 987 (1966).

[67] R. Bennewitz, C. Günther, M. Reichling, E. Matthias, S. Vijayalakshmi, A.V. Barnes, N.H. Tolk. Appl. Phys. Lett. 66, 320 (1995).

[68] L.P. Cramer, B.E. Schubert, P.S. Petite, S.C. Langford. J. Appl. Phys. 97, 074307 (2005). 
[69] M. Huisinga, N. Bouchaala, R. Bennewitz, E.A. Kotomin, M. Reichling, V.N. Kuzovkov, W. von Niessen. Nucl. Instrum. Methods Phys. Res. B 141, 79 (1998).

[70] L.P. Cramer, S.C. Langford, J.T. Dickinson. J. Appl. Phys. 99, 054305 (2006).

[71] A.S. Dworkin, M.A. Bredig. J. Phys. Chem. 75, 2340 (1971).

[72] P.E. Halstead, A.E. Moore. J. Chem. Soc. 0, 3873 (1957).

[73] Т.С. Минакова, И.А. Екимова. Фториды и оксиды щелочноземельных металлов и магния. Поверхностные свойства. Изд. дом Томского гос. ун-та, Томск (2014). 148 с.

[74] K.V. Balen. Cem. Concr. Res. 35, 647 (2005).

[75] V. Nikulshina, M.E. G'alvez, A. Steinfeld. Chem. Eng. J. 129, 75 (2007).

[76] Z. Mirghiasi, F. Bakhtiari, E. Darezereshki, E. Esmaeilzadeh. J. Ind. Eng. Chem. 20, 113 (2014).

[77] F. Beuneu, C. Florea, P. Vajda. Radiat. Eff. Defects Solids 136, 175 (1995).

[78] A. Lust. Dissertation. Institute of Chemical Physics, University of Tartu, Estonia (2007). P. 43.

[79] S.V. Kuznetsov, V.Yu. Proydakova, O.A. Morozov, V.G. Gorieva, M.A. Marisov, V.V. Voronov, A.D. Yapryntsev, V.K. Ivanov, A.S. Nizamutdinov, V.V. Semashko, P.P. Fedorov. Nanosystems: Phys. Chem. Math. 9, 663 (2018).

[80] N.D. Alharbi. J. Nanomater. 2015, 136957 (2015).

[81] N. Salah, N.D. Alharbi, S.S. Habib, S.P. Lochab. J. Nanomater. 2015, 136402 (2015).

[82] F. Somma, R.M. Montereali, M.A. Vincenti, S. Polosan, M. Secu. Phys. Proc. 2, 211 (2009).

[83] S. Rix, U. Natura, F. Loske, M. Letz, C. Felser, M. Reichling. Appl. Phys. Lett. 99, 261909 (2011)

[84] V.M. Orera, E. Alcalá. Phys. Status Solidi A. 38, 621 (1976).

[85] T. Aokia, L.A.J. Garvie, P. Rezc. Ultramicroscopy 153, 40 (2015).

[86] S.Yu. Sokovnin, V.G. Il'ves, M.G. Zuev, M.A. Uimin. J. Phys.: Conf. Ser. 1115, 032092 (2018).

[87] T.J. Glynn, J. Lumin. 48-49, 783 (1991).

[88] O.T. Antonyak, V.V. Vistovskyy, A.V. Zhyshkovych, I.M. Kravchuk. J. Lumin. 67, 249 (2015).

[89] П.В. Фигура, А.И. Непомнящих, Е.А. Раджабов. Оптика и спектроскопия, 65, 940 (1988)

[90] U. Kempe. RMS DPI Fedorov Session 2006. Saint-Petersburg, Russia. 2006-1-58-1, 162 (2006). http://www.minsoc.ru/FilesBase/2006-1-58-1.pdf

[91] R.S.W. Braithwaite, W.T. Flowers, R.N. Haszeldine, M. Russell. Min. Mag. 39, 401 (1973).

[92] R. Thaoklua, J. Janjaroen, K. Tedsree. Chiang Mai. J. Sci. 45, 973 (2018).

[93] H. Petitjean, C. Chizallet, J.M. Krafft, M. Che, H. LauronPernot, G. Costentin. Phys. Chem. Chem. Phys. 12, 14740 (2010).

[94] O. Nakhaei, N. Shahtahmassebi, M. Rezaeeroknabadi, M.M.B. Mohagheghi. Sci. Iran. 19, 1979 (2012).

[95] R. Rao, H.N. Bose. Physica 52, 371 (1971).

[96] M. Topaksu, V. Correcher, J. Garcia-Guinea. Rad. Phys. Chem. 119, 151 (2016).

[97] T. Kogure, K. Saiki, M. Konno, T. Kamino. Mat. Res. Soc. Proc. 504, 183 (1996).

[98] V. Denks, T. Savikhina, V. Nagirnyi. Appl. Surf. Sci. 158, 301 (2000)
[99] Е.П. Чинков, В.Ф. Штанько. ФТТ 40, 1226 (1998).

[100] V. Denks, A. Maaroos, V. Nagirnyi, T. Savikhina, V. Vassiltsenko. J. Phys. Cond. Mater. 11, 3115 (1999).

[101] J.P. Russell. Proc. Phys. Soc. 85, 194 (1965).

[102] В.Г. Мазуренко, М.Г. Зуев. ФТТ 34, 2785 (1992).

[103] I. Alencar, J. Ruiz-Fuertes, K. Schwartz, C. Trautmann, L. Bayarjargal, E. Haussühl, B. Winklere. J. Raman Spectrosc. 47, 978 (2016).

[104] J.M.D. Coey. Solid State Sci. 7, 660 (2005).

[105] K. Ackland, J.M.D. Coey. Phys. Rep. 746, 39 (2018).

[106] R.K. Singhal, P. Kumari, A. Samariya, S. Kumar, S.C. Sharma, Y.T. Xing, E.B. Saitovitch. Appl. Phys. Lett. 97, 172503 (2010).

[107] K. Fabian, V.P. Shcherbakov, S.A. McEnroe. Geochem. Geophys. Geosyst. 14, 947 (2013).

Редактор Ю.Э. Китаев 